\section{Journal of Applied Research and Technology}

www.jart.icat.unam.mx

Journal of Applied Research and Technology 17 (2019) 213-249

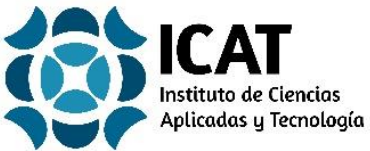

Original

\title{
The design of a liquefied natural gas (LNG) distribution network of a company operating in Mexico
}

\author{
Samuel López-Ruíza , Rafael Bernardo Carmona-Benítez ${ }^{\mathrm{b}^{*}}$ \\ ${ }^{a}$ Engineer Manager, Gas Natural GANAMEX, Letrán Valle 03650, Ciudad de México, México \\ ${ }^{b}$ Business and Economics School, Universidad Anáhuac México, Huixquilucan 52786, Estado de México, México
}

\begin{abstract}
This paper presents a modification of the Multi Depot Multi Period Vehicle Routing Problem with heterogeneous fleet (MDMPVRPHF) to consider capital expenditures and operating expenses (MDMPVRPHFMR). The aim is to design a product distribution network and minimize the total delivery cost. The MDMPVRPHF only considers transportation costs with transportation restrictions. In this paper, the purpose is to solve a real-life freight distribution problem that considers capital expenditures and operations expenses. The MDMPVRPHFMR is formulated as a mixed integer programming model. The results of the application of both models to a real case of study demonstrate the advantages presented by the MDMPVRPHFMR over the MDMPVRPHF. Hence, management restrictions must be considered when designing a real-life freight distribution problem. The study case is to develop a liquefied natural gas distribution model based on a real company operating in Mexico.
\end{abstract}

Keywords: Vehicle routing problem; freight distribution; supply chain management; heterogeneous fleet; multi depot; multi period

\section{INTRODUCTION}

This paper presents a real-life problem for the design of an opening hazardous material production and distribution network by optimizing capital expenditures (CAPEX) and operating expenses (OPEX). The problem presents a high degree of complexity, mostly because both CAPEX and OPEX play a major role in the feasibility of the venture. CAPEX includes buying machinery, acquiring permits, and investment in transport vehicles (fleet size), whereas OPEX involves

\footnotetext{
${ }^{*}$ Corresponding author.

E-mail address: rafael.carmona@anahuac.mx(Rafael Bernardo Carmona-Benítez).

Peer Review under the responsibility of Universidad Nacional Autónoma de México.
}

a hazardous material to the customers (truck drivers and truck fuel) and the raw material costs.

The problem considers that a company has evaluated several locations on which to install the processing of a product and distribute from there to different customer's locations. The transportation is considered as in-house, reason why the fleet size and vehicles capacities are a decision of the owners or investors of the company. The company business model requires the customers to sign a take-or-pay off contract in which it is obligated to pay for a specific amount of product independent on whether it is consumed or not. This business model allows for the planning of the whole contract period by the selection of supply stations, machinery and transport routes. 
In this paper, a new version of the Multi Depot Multi Period Vehicle Routing Problem with heterogeneous fleet (MDMPVRPHF) is proposed. In this version, CAPEX are included to the MDMPVRPHF model as a set of restrictions that must be considered to design a better freight distribution network. We called this model the Multi Depot Multi Period Vehicle Routing Problem with heterogeneous fleet and management restrictions (MDMPVRPHFMR).

The MDMPVRPHF and the MDMPVRPHFMR are variants of the vehicle routing problem (VRP). The VRP is introduced by Dantzig and Ramser (1959). It is the generalization of the Traveling Salesman Problem (TSP) presented by Flood (1956). The classic VRP aims to design a network by minimizing distances, travel times or transportation costs. The network is defined on a graph

$G=(V, \varepsilon, C)$, where $V=\left\{V_{0}, \ldots, V_{n}\right\}$ is a set of vertices, $\varepsilon=\left\{\left(V_{i}, V_{j}\right) \mid\left(V_{i}, V_{j}\right) \in V^{2}, i \neq j\right\}$ is the arc set; and

$C=\left(C_{i j}\right)_{(V i, V j) \in \varepsilon}$ is a cost matrix defined over $\varepsilon$. The depot is vertex $V_{0}$ and the customers to be served are represented by the remaining vertices $V$ (Pillac, Gendreau, Guéret, \& Medaglia, 2013). The classic VRP consists in designing a network by finding a set of routes for a fleet of vehicles with the same capacity, customer's demands are known and supplied by only one vehicle (Archetti \& Speranza, 2008).

Different VRP variants have been developed. The most studied are the Capacitated VRP (CVRP), the VRP with time Windows (VRPTW), the VRP with Pick-up and Delivery (PDP), the Split Delivery Vehicle Routing Problem (SDVRP), and the Heterogeneous fleet VRP (HVRP).

In the CVRP, a set of customers have a different demand for a good and the fleet of vehicles have finite capacity (Pillac et al., 2013). The VRPTW designs routes from one depot to a set of dispersed customers who can be supplied once by only one vehicle in a time interval, every route starts and ends at the depot, the total demand transported per route (sum of the demands of all points in a route) cannot exceed the capacity of the vehicle (Braysy \& Gendreau, 2005). In the PDP, a specific amount of goods must be picked-up and delivered to customers (Pillac et al., 2013). Contrary to the classical VRP, the SDVRP does not consider the restriction that customers are supplied by only one different capacities and costs is available for the distribution of goods (Baldacci, Battarra, \& Vigo, 2008).

In the literature, there are many variations of the HVRP problem with vehicles capacities constraints and with time window constraints to consider multiple depots, multiple trips to be operated by the vehicles, multiple vehicles with different capacities and other operational constraints. These HVRP variations are the Heterogeneous VRP with Fixed Costs and Vehicle Dependent Routing Costs (HVRPFD), the Heterogeneous VRP with Vehicle Dependent Routing Costs (HVRPD), the Fleet Size and Mix VRP with Fixed Costs and Vehicle Depending Routing Costs (FSMFD), the Fleet Size and Mix VRP with Vehicle Dependent Routing Costs (FSMD), the Fleet Size and Mix VRP with Fixed Costs (FSMF), and the SiteDependent VRP (SDVRP) (Baldacci et al., 2008).

Goel and Gruhn (2008) study the VRP in real-life applications, and they find different difficulties to be considered. In real-life, the VRP must consider a heterogeneous fleet of vehicles, time window restrictions, differing travel times and costs, vehicles capacity, facility capacity, vehicle compatibility with specific orders, multiple pick-ups per order, delivery locations, service locations, orders where a vehicle can start and finish a journey at different locations, and vehicle route restrictions such as maximum sizes and weights. They include these difficulties as restrictions into the classic VRP and therefore, they formulate the General Vehicle Routing Problem (GVRP). Based on the GVRP, Mancini (2016) develops the MDMPVRPHF. In her study, Mancini explains that real-life cargo distribution problems have a high degree of complexity because of multi-dimensional vehicle capacity constraints, characteristics of the vehicles, route lengths and travel times, time windows, the compatibility between products, the compatibility between products and vehicles, the compatibility between customers and vehicles, and objective functions which consider different costs such as transportation costs, inventory costs, opportunity costs, etc.

In this article, the MDMPVRPHFMR recognizes the MDMPVRPHF restrictions and adds and proves that CAPEX and OPEX must be considered to design a freight distribution network much closer to real-life. Therefore, the MDMPVRPHFMR includes CAPEX 
transport vehicles) and OPEX (raw material cost and transportation of product to the customers such as truck drivers and truck fuel).

This article presents the application of the MDMPVRPHFMR to a real-life problem for the design of an opening liquefied natural gas (LNG) distribution network for a planning time horizon. In this study case, the CAPEX and OPEX information of a real company is used to design its distribution network prior to establishing a contract with the client. The model simultaneously optimizes location allocation, production capacity and vehicle routing decisions. To solve the problem, we present optimal solutions for different random variables small instances using the optimization software CPLEX from IBM. The customers' demands and the distances between nodes (suppliers and customers) have been generated using Mersenne Twister which is a random number generator. These values are different for each instance and they are presented in Appendix A.

The paper is organized as follows. In Section 2, the MDMPVRPHF and the MDMPVRPHFMR problems are described and the mixed integer linear programming models are presented. In Section 3, the study case is presented together with the computing results of the application of the MDMPVRPHF and the MDMPVRPHFMR models. Section 4 presents the aleatory instances used to test the MDMPVRPHF and the MDMPVRPHFMR models and their computing results. Finally, conclusions and references are included.

\section{MDMPVRPHFMR PROBLEM DESCRIPTION AND MATHEMATICAL}

\subsection{MDMPVRPHFMR PROBLEM DESCRIPTION}

The company's business model is to deliver a steady, guaranteed and contractual supply of natural gas to its customers. To produce LNG, a liquefaction plant and access to a natural gas pipeline are needed. Since the natural gas pipeline network in Mexico is not vast, there are industrial plants that do not have access to natural gas via pipeline, and their natural gas consumption must be delivered by truck as compressed natural gas (CNG) or LNG. A typical supply chain of LNG consists of a liquefaction plant that is connected to the natural gas liquefaction plant that is connected to the natural gas pipeline, terrestrial transport of the LNG via trucks and a vaporization plant that converts the LNG into natural gas to be consumed as fuel in the client's installations. Storage may be added in the liquefaction plant and in the customer's plant as buffer to account for transport eventualities.

When a customer quotes a LNG contractual supply, the company has to determine the nearest feasible connections to the natural gas pipeline in which liquefaction plan must be installed and the possible terrestrial routes to deliver the LNG to the client. The investment required for LNG plants is high, therefore a long-term supply take-or-pay contract is signed between the customer and the company, in which the customer is obligated to pay for a specific amount of product independent on whether it is consumed or not. This long-term contract requires the company to consider and minimize the transportation costs, since after five or seven years, the transportation costs may be greater than the initial investment.

The different feasible connections to a natural gas pipeline that the company evaluates to supply LNG to a customer, bring several variables into consideration: land cost, permit costs, natural gas (raw material) cost, and different routes to the customer plant(s). The natural gas cost within the pipelines is not fixed territory wise and therefore dependent on the location. It can be concluded that the location of the processing and distribution plant is correlated with the operation costs, and this presents a high degree of complexity.

Since CAPEX and OPEX are correlated, the model's objective is to minimize both simultaneously. The decisions of the MDMPVRPHFMR problem are to locate a set of supply stations, allocate supply stations to customers, select the distribution routes, manage the fleet, and select the machinery in the supply stations. The aim is to meet customer demand by designing an optimal network for the company for a planning horizon at minimum total cost.

The MDMPVRPHFMR requires solving investment in infrastructure and transport decisions. These former decisions are long-term or strategic decisions (Miranda \& Garrido, 2004). The investment in infrastructure decisions are: location of supply stations through time and buying machines for production capacity. These decisions are long-term decisions that require high 
investment (Current, Ratick, \& Revelle, 1997) because of the cost associated with property acquisition and facility construction (Owen \& Daskin, 1998). The transport decisions are: the management of the fleet and its size, vehicles capacities (heterogeneous fleet), and routes selection. These decisions are long-term decisions that depend on operation costs, supply, and demand. The product transportation is considered as in-house and the allocation of supply stations to customers can change over time, normally every year (Vidal \& Goetschalckx, 1997; Current et al., 1997). The MDMPVRPHFMR considers a multi-period approach and the flexibility for a vehicle to end the route at another supply station. The supply station capacity, vehicle capacity and inventory control introduced by Coelho and Laporte (2012) are restrictions also included in the MDMPVRPHFMR. Besides these restrictions, the MDMPVRPHFMR adds the cost of opening of supply stations (permits, city gate, civil), penalties for service times, machinery selection, raw material costs and fleet size.

\section{A. Assumptions}

- Costumer demands are independent and location are known.

- Once a supply station is located, they cannot be relocated.

- The company pays a fixed location cost for opening a supply station.

- The company pays a fixed cost for the natural gas in a supply station.

- Once the machines are installed in a supply station, they cannot be moved to another supply station.

- Vehicles capacities are known (heterogeneous fleet).

- The natural gas costs remain the same throughout the optimization period in each supply station.

- The CAPEX are amortized through the optimization period, which usually is equal to the customer's contract period.

- 28.00 standard cubic meters of natural gas [m3] are equal to 1 million of British Thermal Units [mmBtu] of LNG which is the standard unit used in this industry, but for scientific purposes, in this paper we use cubic meters.

\section{B. Decisions}

- Location, production capacity and allocation decisions: number of supply stations to locate, where to locate them, set their production capacities, and allocate customers to them.

- Fleet size decisions: number of vehicles to use.

- Routing decisions: What routes to operate, Vehicles must start their journey from a supply station and serve their allocated customers. Hence, the solutions include multi-period routes.

The assumptions and decisions are incorporated in a mathematical programming model presented in Section D. Its notation is introduced in Section C.

\section{Definition and notations}

The model works with a set of nodes, a set of supply stations, a set of customers, a set of routes, and a set of vehicles.

$-V=\{1 \ldots v\}$ is the set of homogenous vehicles

$-K=\{1 \ldots k\}$ is the set of routes

$-I=\{1 \ldots i\}$ is the set of supply stations

$-J=\{1 \ldots j\}$ is the set of customers

$-M=\{1 \ldots m\}$ is the set of machines

$-N=I \cup J=\{1 \ldots i\} \cup\{i+1 \ldots i+j\}$ is the set of nodes

Therefore, the total number of nodes is $n+m$, where and the maximum number of routes for all vehicles is $k \in \mathrm{K}$.

\section{1) Variables}

The Boolean variables are:

$-x_{i j_{k}}^{v}$ is a directed routing variable equal to 1 if arc $i j$, with $i \in N, j \in N$, is used by a vehicle $v \in V$ in route $k \in K, 0$ otherwise

$[-]$

- $y_{i_{k}}^{v}$ is equal to 1 if node $i \in N$ is visited by a vehicle $v \in$ $V$ in route $k \in K, 0$ otherwise

$-L_{i_{k}}^{v}$ specifies if vehicle $v \in V$ starts a journey from the supply station $i \in I$ in route $k \in K, 0$ otherwise $\quad[-]$

$-Z_{i_{k}}^{v}$ is equal to 1 if route $k \in K$ for vehicle $v \in V$, 
- $u^{v}$ is equal to 1 if vehicle $v \in V$ is used in the solution, 0 otherwise

$-P_{i}$ is equal to 1 when node $i \in I$ is used in the solution, 0 otherwise

The integer variables are:

- $g_{i}^{m}$ indicates how many machines $m \in M$ are selected for supply station $i \in I$

The continuous variables are:

- $q_{i j_{k}}^{v}$ is the quantity delivered to costumer $j \in J$ by vehicle $v \in V$ in route $k \in K$ departing from $i \in I$ [m3]

$-C C_{i}$ is the required production capacity for $i \in I \quad[\mathrm{~m} 3 / \mathrm{h}]$

$-W_{k}^{v}$ is the traveling time of vehicle $v \in V$ in route $k \in$ $K$

$-T_{i_{k}}^{v}$ is the time schedule in which node $i \in N$ is visited by vehicle $v \in V$ in route $k \in K$

\section{2) Parameters}

The parameters are:

- $\alpha$ the maximum route duration

$[\mathrm{h}]$

$-s$ the vehicles average speed $[\mathrm{km} / \mathrm{h}]$

$-\Theta$ the planning time horizon is the time per day available to operate

$-Q_{j}$ daily demand per location $j \in J$

$-C^{v}$ the transport capacity per vehicle $v \in V$

[m3]

- $r_{i j}$ the distance matrix, with $i \in N, j \in N$

$[\mathrm{m} 3]$

- $\mu^{v}$ the cost of usage per vehicle $v \in V$

- $\rho_{i}$ the cost of opening a supply station $i \in I$ [\$/day]

- $\varrho_{i}$ the raw material cost in a supply station $i \in I \quad[\$ / \mathrm{m} 3]$

$-p^{m}$ the cost of machine $m \in M$

$[\$ /$ day $]$

$-c^{m}$ the production capacity of machine $m \in \mathrm{M} \quad$ [m3/day]

$-\delta_{j}$ the time to discharge/charge material from vehicles to customers $j \in J$

$-\gamma$ a penalty cost in visit times

- $\beta$ the cost of renting/buying the vehicle

[\$/day

- Num $_{j}$ the number of days in contract with customer $j \in J$

[days]

- $f c_{j}$ the fuel consumed by customer $j \in J$ during $\mathrm{Num}_{j}$

[m3]

- margin $_{j}$ the company's margin for supplying customer $j \in J$

$[\$ / \mathrm{m} 3]$

\section{3) Costs and Price definitions}

- CAPEX is the company capital expenditures

[\$/day]

- OPEX is the company operating expenses

[\$/day]

- TRA is company the daily transport costs

[\$/day]

- $V E H$ is the company the daily vehicle rent costs [\$/day]

- PEN is the company daily cost for customer time services

$[\$ /$ day $]$

- $R A W$ is the company daily raw material costs $\quad[\$ /$ day]

— INV is the company daily cost for opening a supply station

[\$/day]

- $M C H$ is the company daily machines costs in the supply stations

[\$/day]

$-S_{j}$ is the company fuel price to customer $j \in J$

$[\$ / \mathrm{m} 3]$

The cost of opening a supply station $\rho_{i}$, the cost of the machines $p^{m}$, and the cost of buying or renting vehicles $\beta$ are expressed in [\$/day] by dividing the cost by Num .

\section{Mixed Integer Programming model (MIP)}

The main objective of a LNG distribution company is to maximize its utilities by offering different fuel price to its customers depending on the number of days in contract, the amount of fuel consumed, and the company's margin. The fuel price $\left(S_{j}\right)$ to the customer $j \in J$ is calculated as the sum of all the company costs (CAPEX and OPEX) divided by the amount of fuel consumed plus the profit margin of the company:

$S_{j}=\frac{C A P E X+O P E X}{f c_{j}}+\operatorname{margin}_{j}$

The CAPEX and OPEX are considered daily costs and then multiplied by the total number of days of the optimization period. The daily costs are expressed as a CAPEX and OPEX in equation (2).

$S_{j}=\frac{N u m_{j}^{*}(C A P E X+O P E X)}{f c_{j}}+\operatorname{margin}_{j}$

The OPEX costs are TRA, VEH, PEN, and RAW, and the CAPEX costs are $I N V$ and $M C H$. The TRA, $V E H, P E N$, and $R A W$ are daily costs throughout the contract period. The $I N V$ and $M C H$ costs are paid at the beginning of the contract and must be divided by the 
planning time horizon. To optimize all the costs simultaneously, the model is set to optimize per day, therefore the $I N V$ and $M C H$ costs are amortized along the contract period and considered as daily payment. By substituting the CAPEX and OPEX costs, equation (2) becomes:

$S_{j}=\frac{N u m_{j} *(T R A+V E H+P E N+R A W+I N V+M C H)}{f c_{j}}+\operatorname{margin}_{j}$

Since $\mathrm{Num}_{j}, f c_{j}$ and $\operatorname{margin}_{j}$ are not variables, but parameters, the maximization of the LNG distribution company utility is achieved by minimizing the company's CAPEX and OPEX.

\section{1) Objective function}

In this paper, we propose to modify the MDMPVRPHF model objective function to consider CAPEX and OPEX. In this paper, we propose two modifications to the MDMPVRPHF to include management restrictions. The first modification considers TRA, VEH, PEN, RAX, INV, and $M C H$ costs, we called this model the MDMPVRPHFMR model because it includes management restrictions considering production. The second modification only considers TRA, VEH, $P E N$, and $I N V$ costs, we called this model the MDMPVRPHFMRWP model because it includes management restrictions without considering production.

The MDMPVRPHFMR model aims to minimize the TRA, VEH, PEN, RAX, INV, and $M C H$ costs, hence achieving a lower fuel price $\left(S_{j}\right)$ for the customer and higher profit for the company. The objective function for the MDMPVRPHFMR model is shown in equation (4a).

$$
\begin{aligned}
\min f= & \sum_{i \in N} \sum_{j \in N} \sum_{k \in K} \sum_{v \in V} r_{i j} \mu^{v} x_{i j_{k}}^{v}+\sum_{v \in V} \beta u^{v}+\sum_{i \in N} \sum_{k \in K} \sum_{v \in V} \gamma y_{i_{k}}^{v} \\
& +\sum_{i \in I} \rho_{i} P_{i}+\sum_{i \in I} \varrho_{i} C C_{i}+\sum_{i \in I} \sum_{m \in M} g_{i}^{m} p_{i}^{m}
\end{aligned}
$$

The objective function first term is the daily $T R A$. The second term is the daily $V E H$. The third term is the penalty cost $P E N$ in time spent visiting customers. The fourth term is the daily raw material costs $R A W$. The fifth term is the daily amortization of the opening costs $I N V$. The last term is the daily amortization of the machine cost $M C H$.

The MDMPVRPHFMRWP model aims to minimize the TRA, VEH, PEN, and INV costs. The objective function for the MDMPVRPHFMRWP model is shown in equation (4b).

$$
\begin{aligned}
\min f= & \sum_{i \in N} \sum_{j \in N} \sum_{k \in K} \sum_{v \in V} r_{i j} \mu^{v} x_{i j_{k}}^{v}+\sum_{v \in V} \beta u^{v} \\
& +\sum_{i \in N} \sum_{k \in K} \sum_{v \in V} \gamma y_{i_{k}}^{v}+\sum_{i \in I} \rho_{i} P_{i}
\end{aligned}
$$

Finally, the MDMPVRPHF model proposed by Mancini (2016) aims to minimizes only the TRA costs. The objective function for the MDMPVRPHF model is shown in equation (4c).

$$
\min f=\sum_{i \in N} \sum_{j \in N} \sum_{k \in K} \sum_{v \in V} r_{i j} \mu^{v} x_{i j_{k}}^{v}
$$

\section{2) Mixed Integer Programming model (MIPM)}

The mathematical formulation is as follows:

s.t.

$\sum_{i \in N \mid i \neq j} x_{j i}^{v}=y_{j_{k}}^{v} \quad \forall j \in J, \forall k \in K, \forall v \in V$

$\sum_{i \in N \mid i \neq j} x_{i j_{k}}^{v}=y_{j_{k}}^{v} \quad \forall j \in J, \forall k \in K, \forall v \in V$

$$
\sum_{\substack{j \in N \mid i \neq j \\ \forall i \in I, \forall k \in K}} x_{i j_{k}}^{v}+\sum_{j \in N \mid i \neq j} x_{j i_{k}}^{v} \leq 2 y_{i_{k}}^{v}
$$

$\forall i \in I, \forall k \in K, \forall v \in V$

$\sum_{j \in N \mid i \neq j} x_{i j_{k}}^{v} \leq L_{i_{k}}^{v} \quad \forall i \in I, \forall k \in K, \forall v \in V$

$x_{i j_{k}}^{v} \leq y_{i_{k}}^{v} \quad \forall i \in N, \forall j \in N, \forall k \in K, \forall v \in V$

$y_{j_{k}}^{v} \leq y_{i_{k}}^{v} \quad \forall i \in I, \forall j \in J, \forall k \in K, \forall v \in V$

$\sum_{j \in N, j \neq i} x_{i j_{k}}^{v}=Z_{i_{k}}^{v} \quad \forall i \in I, \forall k \in K, \forall v \in V$

$\sum_{i \in I} \sum_{j \in N \mid i \neq j} x_{i j_{k}}^{v}=\sum_{i \in I} Z_{i_{k}}^{v} \quad \forall k \in K, \forall v \in V$

$\sum_{j \in J} y_{j_{k}}^{v} \leq \eta * \sum_{i \in I} Z_{i_{k}}^{v}$

$\forall k \in K, \forall v \in \mathrm{V}$, is a very large constant 
$T_{j_{k}}^{v} \geq T_{i{ }_{k}}^{v}+\frac{1}{S} r_{i j} x_{i j_{k}}^{v}-\Theta\left(1-x_{i j_{k}}^{v}\right)$

$\forall i \neq j, \forall i \in N, \forall j \in J, \forall k \in K, \forall v \in V$

$T_{i}=0 \quad \forall i \in I$

$W_{k}^{v}=\sum_{i \in N} \sum_{j \in N} \frac{1}{s} r_{i j} x_{i j_{k}}^{v}+\sum_{i \in N} \sum_{j \in N} \delta_{i} y_{i j_{k}}^{v}$

$\forall k \in K, \forall v \in V$

$W_{k}^{v} \leq \alpha \sum_{i \in I} Z_{i_{k}}^{v} \quad \forall k \in K, \forall v \in V$

$\sum_{i \in I} \sum_{j \in J} q_{i j_{k}}^{v} \leq C^{v} \sum_{i \in I} Z_{i_{k}}^{v} \quad \forall k \in K, \forall v \in V$

$\sum_{i \in I} q_{i j_{k}}^{v} \leq Q_{j} y_{j_{k}}^{v} \quad \forall j \in J, \forall k \in K, \forall v \in V$

$\sum_{v \in V} \sum_{k \in K} \sum_{i \in I} q_{i j_{k}}^{v}=Q_{i} \quad \forall j \in J$

$\sum_{i \in I} L_{i_{k}}^{v} \leq 1 \quad \forall k \in K, \forall v \in V$

$L_{i_{k}}^{v}=\sum_{j \in N} x_{j i_{w}}^{v}$

$\forall i \in I, \forall v \in V, \forall w \in K \mid w=k-1$

$u^{v} \geq \sum_{i \in I} Z_{i_{k}}^{v} \quad \forall v \in V, k=1$

$\sum_{k \in K} W_{k}^{v} \leq \Theta \quad \forall v \in V$

$\sum_{v \in V} \sum_{k \in K} \sum_{j \in N \mid i \neq j} x_{i j_{k}}^{v} \leq \eta * P_{i}$

$\forall i \in I, \eta$ is a very large constant

$C C_{i}=\sum_{v \in V} \sum_{k \in K} \sum_{j \in J} q_{i j_{k}}^{v} \quad \forall i \in I$

$\sum_{m \in M} g_{i}^{m} c_{i}^{m} \geq C C_{i} \quad \forall i \in I$

$T_{j_{k}}^{v} \leq \alpha y_{j_{k}}^{v} \quad \forall j \in J, \forall k \in K, \forall v \in V$

$q_{i j_{k}}^{v} \geq 0 \quad \forall i \in I, \forall j \in J, \forall k \in K, \forall v \in V$

$L_{i_{k}}^{v}=\{0,1\} \quad \forall i \in I, \forall k \in K, \forall v \in V$

$$
\begin{aligned}
& y_{i_{k}}^{v}=\{0,1\} \quad \forall i \in N, \forall k \in K, \forall v \in V \\
& Z_{i_{k}}^{v}=\{0,1\} \quad \forall i \in I, \forall k \in K, \forall v \in V \\
& x_{i_{j_{k}}=\{0,1\}} \quad \forall i \in N, \forall j \in N, \forall k \in K, \forall v \in V \\
& u^{v}=\{0,1\} \quad \forall v \in V \\
& C C_{i} \geq 0 \quad \forall i \in I \\
& g_{i}^{m} \geq\{0,1,2, \ldots, \infty\} \quad \forall i \in I, \forall m \in M,
\end{aligned}
$$

Constraints (5) and (6) ensure that a customer is only visited on a route if it is assigned to that route. Constraint (7) allows the vehicle to return to the supply station from which it departed. Constraint (8) implies that the arcs leaving a supply station may be used only if the vehicle $v \in V$ is located in that supply station in the previous route $(k-1)$. Constraints (9) and (10) are logical inequalities. Constraints (11) and (12) indicate that if vehicle $v \in V$ travels in route $k \in K$, it must depart from and arrive at a supply station $i \in I$. Constraint (13) states that a customer $j \in J$ can be assigned to route $k \in K$ only if the route is used. Constraints (14) and (15) guarantee sub tour elimination. Constrains (16) and (17) limit vehicle $v \in V$ travelling time. Constraints (18) restricts vehicle $v \in V$ capacity. Constraint (19) ensures no product quantity is delivered if customer $j \in J$ is not assigned to route $k \in$ $K$. Constraint (20) guarantees that during period $\Theta$, the total quantity required is delivered. Constraints (21) and (22) determine the starting supply station $i \in I$ for each route $k \in K$, depending on the final location of vehicle $v \in V$ on the previous route $k \in K$. Constraint (23) determines if the vehicle $v \in V$ is used. Constraint (24) defines the planning time horizon. Constraint (25) determines if supply station $i \in I$ is used. Constraint (26) states the production capacity required in supply station $i \in I$. Constraint (27) guarantees the machines $m \in M$ selected can produce the capacity required for each supply station $i \in I$. Constraint (30) specifies that if a location is not visited, no time can be assigned to it. Finally, constraints (29) to (36) specify the variable domain. 


\section{STUDY CASE}

In this Section, a real-life study case is presented to evaluate the performance of the proposed MDMPVRPHFMR model against the performance of the MDMPVRPHFMRWP model and the MDMPVRPHF model. For the real-life study case, the names of the locations are confidential and therefore not shown.

In this study case, the currency is USD and the input data is as follows: a contract period of 5 years, the maximum route travelling time $\alpha$ is equal to 10 [h], the vehicles average speed $s$ is equal to $50[\mathrm{~km} / \mathrm{h}]$, the planning time horizon $\Theta$ is equal to 24 [h], the transport capacity per vehicle $C^{v}$ is equal to $23,128 \mathrm{~m} 3$ of $\mathrm{LNG}$, the cost of usage per vehicle $\mu^{v}$ is equal to $0.526[\$ / \mathrm{km}]$, the time to discharge/charge the hazardous material from the vehicle to each customer $\delta_{j}$ is equal to $0.5[\mathrm{~h}]$, the penalty cost in time $\gamma$ is $20[\$]$, the cost of renting/buying the vehicle $\beta^{v}$ is equal to $6.36[\$ / \mathrm{h}]$ and the machines production capacity of LNG $c_{i}^{m}$ is equal to $863.33[\mathrm{~m} 3 / \mathrm{h}]$.

The cost of opening the supply stations are shown in Table 1. This costs correspond to the legal paperwork and a physical installations needed to connect the station to a natural gas supply, which is the raw material. In the case of Supply Station 2 (SS_2), there is no cost because the client already has a connection to the natural gas pipe line. The supply station opening cost $\rho_{i}$ for Supply Station 1 (SS 1) and Supply Station 3 (SS_3) for a 5year contract period is $\rho_{1}=\rho_{3}=500,000 /\left(5^{*} 365\right)=$ 273.97 [\$/day].

Table 1. Supply Station Opening Costs in USD

\begin{tabular}{ll}
\hline $\begin{array}{l}\text { Supply } \\
\text { node }\end{array}$ & Opening Costs [\$] \\
\hline SS_1 & $500,000.00$ \\
SS_2 & 0.00 \\
SS-3 & $500,000.00$ \\
\hline
\end{tabular}

Table 2 shows the distance between nodes or between supply stations and customers in $\mathrm{km}$. Where Customer 1 (C_1), Customer 2 (C_2) and Customer 3 (C_3) are three demand nodes for the same customer and SS _1, SS_2 and SS_3 are the three possible supplier stations.

The total amount of fuel consumed by the three demand nodes (C_1, C_2 and C_3) for a 5-year contract period is $412,836,900[\mathrm{~m} 3]$.
Table 2. Distance between nodes for case study in $\mathrm{km}$.

\begin{tabular}{lllllll}
\hline & C_1 & C_2 & C_3 & SS_1 & SS_2 & SS_3 \\
\hline C_1 & 0 & 210 & 122 & 126 & 30 & 245 \\
C__2 & 210 & 0 & 98 & 86 & 180 & 54 \\
C_3 & 122 & 98 & 0 & 32 & 92 & 118 \\
SS_1 & 126 & 86 & 32 & 0 & 94 & 96 \\
SS_2 & 30 & 180 & 92 & 94 & 0 & 202 \\
SS_3 & 245 & 54 & 118 & 96 & 202 & 0 \\
\hline
\end{tabular}

The customer demand nodes are shown in Table 3.

Table 3. Daily demand per location.

\begin{tabular}{cc}
\hline Customer node & Daily demand [m3/day] \\
\hline C_1 & $32,424.00$ \\
C_2 & $130,788.00$ \\
C_3 & $63,000.00$ \\
\hline
\end{tabular}

Fig. 1 shows the results for the application of the MDMPVRFHF model. In Fig. 1, Fig. 2 and Fig. 3, the dark circles indicate supply stations that are not part of the solution, the big dark dots indicate the supply stations that are part of the solution, the little light dots indicate the customer locations and the medium size dots indicate the customer locations where LNG is delivered. Each row corresponds to a vehicle $v \in V$ whereas the columns correspond to the route $k \in K$. Each route has a title, e.g. "V1-R2 T=5.5h" with the following notation: "V" corresponds to the vehicle, " $\mathrm{R}$ " corresponds to the route, " $T$ " corresponds to the time of the route. Vehicle routes are consecutive, it means "R1" happens before "R2", and so on. The quantity delivered of LNG is indicated by the number with an arrow pointing to its location in [m3]. The subscript of the quantity delivered corresponds to the supply station number where that quantity is produced.

The production needed in SS_1, SS_2 and SS_3 to satisfy the customer demands at C_1, C_2 and C_3 are shown in Table 4.

Table 4. Supply Stations productions using the MDMPVRFHF model.

\begin{tabular}{llll}
\hline $\begin{array}{l}\text { Supply } \\
\text { Station }\end{array}$ & $\begin{array}{l}\text { Production } \\
{[\mathbf{m} 3 / \text { day }]}\end{array}$ & $\begin{array}{l}\text { No. of } \\
\text { Machines }\end{array}$ & $\begin{array}{l}\text { Machine } \\
\text { Utilization }\end{array}$ \\
\hline SS_1 & $86,128.00$ & 5 & $83.10 \%$ \\
SS_2 & $32,424.00$ & 2 & $78.20 \%$ \\
SS_3 & $107,660.00$ & 6 & $86.60 \%$ \\
\hline
\end{tabular}



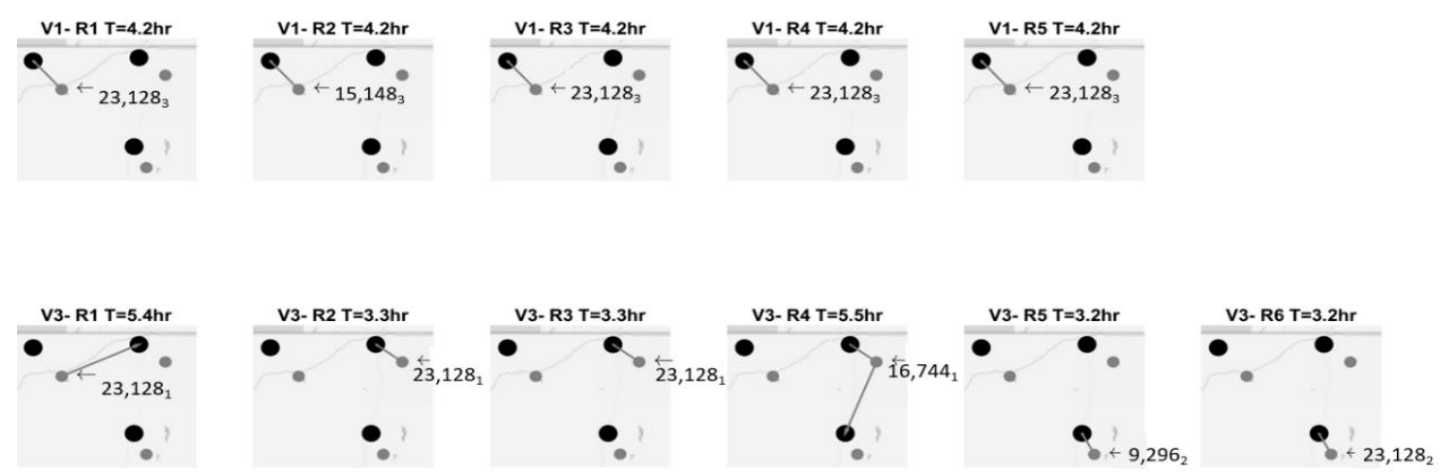

Fig. 1. Transport routes of the solution obtained with the MDMPVRFHF model.

The transport routes using the MDMPVRFHF model are shown in Fig. 1. Vehicle 1 (V1) operates five routes per day and vehicle 2 (V2) operates six routes per day.

Although, in the MDMPVRFHF model only TRA and $V E H$ are minimized, all CAPEX and OPEX costs are considered for the calculation of the customers fuel priceas shown in Table 5 .

Table 5. Case study costs using objective function the MDMPVRFHF model.

\begin{tabular}{lll}
\hline Cost & Total Cost $[\$]$ & Unitary Cost $[\$ / \mathrm{m3}]$ \\
\hline TRA & $1,041,200.00$ & 0.00250 \\
VEH & $557,110.00$ & 0.00143 \\
RAW & $51,605,000.00$ & 0.12500 \\
INV & $1,000,000.00$ & 0.00250 \\
MCH & $48,085,000.00$ & 0.11643 \\
& Total: & 0.24786 \\
\hline
\end{tabular}

The transport routes using the MDMPVRFHFMRWP model are shown in Fig. 2. Vehicle 1 (V1) operates five routes per day, vehicle 2 (V2) operates one route per day, and vehicle 3 (V3) operates five routes per day. The production needed in SS_2 and SS_3 to satisfy the customer demands at C_1, C_2 and C_3 are shown in Table 6. The results indicate that SS_1 is not required to operate, therefore there are no opening costs for this station.

Table 6. Supply Stations productions using the MDMPVRFHFMRWP model.

\begin{tabular}{llll}
\hline $\begin{array}{l}\text { Supply } \\
\text { Station }\end{array}$ & $\begin{array}{l}\text { Production } \\
{[\mathbf{m} 3 / \text { day }]}\end{array}$ & $\begin{array}{l}\text { No. of } \\
\text { Machines }\end{array}$ & $\begin{array}{l}\text { Machine } \\
\text { Utilization }\end{array}$ \\
\hline SS_1 & 0.00 & 0 & - \\
SS_2 & $95,424.00$ & 5 & $92.10 \%$ \\
SS_3 & $130,788.00$ & 7 & $90.20 \%$ \\
\hline
\end{tabular}
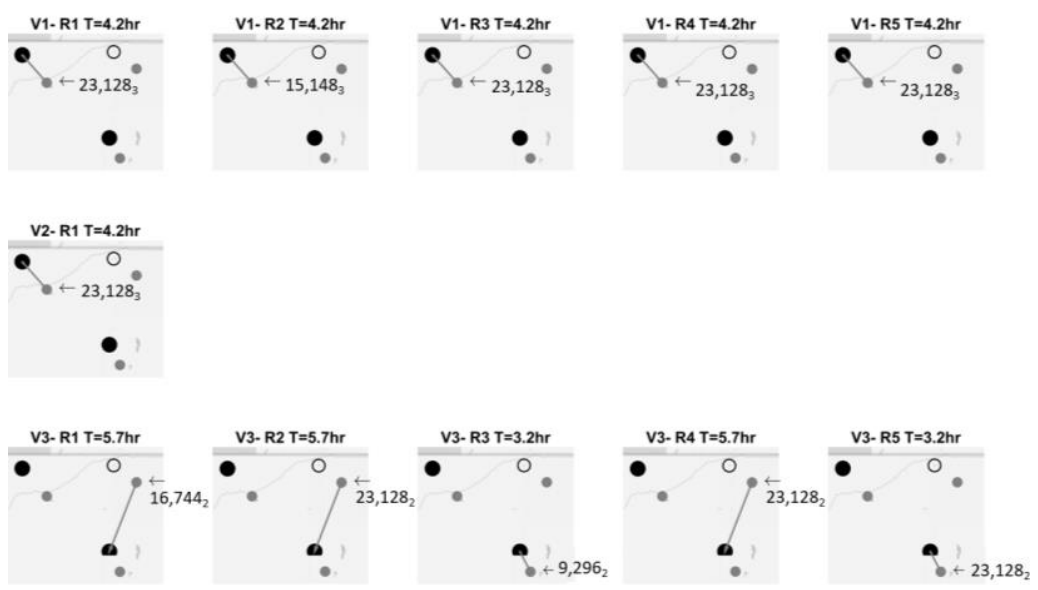

Fig. 2. Transport routes of the solution obtained with the MDMPVRFHFMRWP model. 
Table 7 shows all the costs considered for the customer's fare when using the MDMPVRFHFMRWP model. By comparing the total cost per $\mathrm{m} 3$ of LNG from Table 5 and Table 7 , it is possible to conclude that the total cost is reduced from $\$ 0.24786$ to $\$ 0.23893$ USD. The results demonstrate that the MDMPVRFHFMRWP model achieves lower costs than the MDMPVRFHF model.

Table 7. Case study costs using objective function the MDMPVRFHFMRWP model.

\begin{tabular}{lll}
\hline Cost & Total Cost $[\$]$ & Unitary Cost $[\$ / \mathbf{m} 3]$ \\
\hline $\boldsymbol{T R A}$ & $1,267,900.00$ & 0.00321 \\
$\boldsymbol{V E H}$ & $835,660.00$ & 0.00214 \\
$\boldsymbol{R A} \boldsymbol{W}$ & $51,605,000.00$ & 0.12500 \\
$\boldsymbol{I N} \boldsymbol{V}$ & $500,000.00$ & 0.00107 \\
$\boldsymbol{M} \boldsymbol{C H}$ & $44,387,000.00$ & 0.10750 \\
& Total: & 0.23893 \\
\hline
\end{tabular}

Finally, the transport routes using the MDMPVRFHFMR model are shown in Fig. 3. Vehicle 1 (V1) operates four routes per day, vehicle 2 (V2) operates two routes per day, and vehicle 3 (V3) operates five routes per day. The production needed in SS 1 and SS_2 to satisfy the customer demands at C_1, C_2 and C_3 are shown in Table 8 . The results indicate that SS_3 is not required to operate, therefore there are no opening costs for this station.
Table 8. Supply Stations productions using the MDMPVRFHFMR model.

\begin{tabular}{|c|c|c|c|}
\hline $\begin{array}{l}\text { Supply } \\
\text { Station }\end{array}$ & $\begin{array}{l}\text { Production } \\
{[\mathrm{m} 3 / \text { day }]}\end{array}$ & $\begin{array}{l}\text { No. of } \\
\text { Machines }\end{array}$ & $\begin{array}{l}\text { Machine } \\
\text { Utilization }\end{array}$ \\
\hline SS1 & $206,976.00$ & 10 & $99.90 \%$ \\
\hline SS1 & $19,236.00$ & 1 & $92.80 \%$ \\
\hline SS1 & - & 0 & - \\
\hline
\end{tabular}

Table 9 shows all the costs considered for the customer's fare when using the MDMPVRFHFMR model. By comparing the total cost per $\mathrm{m} 3$ of LNG from Table 5 (\$0.24786), Table 7 (\$0.23893), and Table 9 $(\$ 0.23)$, it is possible to conclude that the minimum total cost, and hence the minimum fuel price $\left(S_{j}\right)$, is reached when using the MDMPVRFHFMR model. Therefore, the results obtained with the proposed MDMPVRFHFMR model indicates that TRA, VEH, PEN, RAX, INV, and $M C H$ costs must be considered. It also demonstrates that the model proposed by Mancini (2016) (the MDMPVRFHFMR model) does not achieve the lowest possible cost.

Table 9. Case study costs using objective function the MDMPVRFHFMR model.

\begin{tabular}{lll}
\hline Cost & Total Cost $[\$]$ & Unitary Cost $[\$ / \mathbf{m} 3]$ \\
\hline $\boldsymbol{T R} \boldsymbol{A}$ & $1,383,100.00$ & 0.00321 \\
$\boldsymbol{V E H}$ & $835,660.00$ & 0.00214 \\
$\boldsymbol{R A} \boldsymbol{W}$ & $51,605,000.00$ & 0.12500 \\
$\boldsymbol{I N} \boldsymbol{V}$ & $500,000.00$ & 0.00107 \\
$\boldsymbol{M C H}$ & $40,688,000.00$ & 0.09857 \\
& Total: & 0.23000 \\
\hline
\end{tabular}
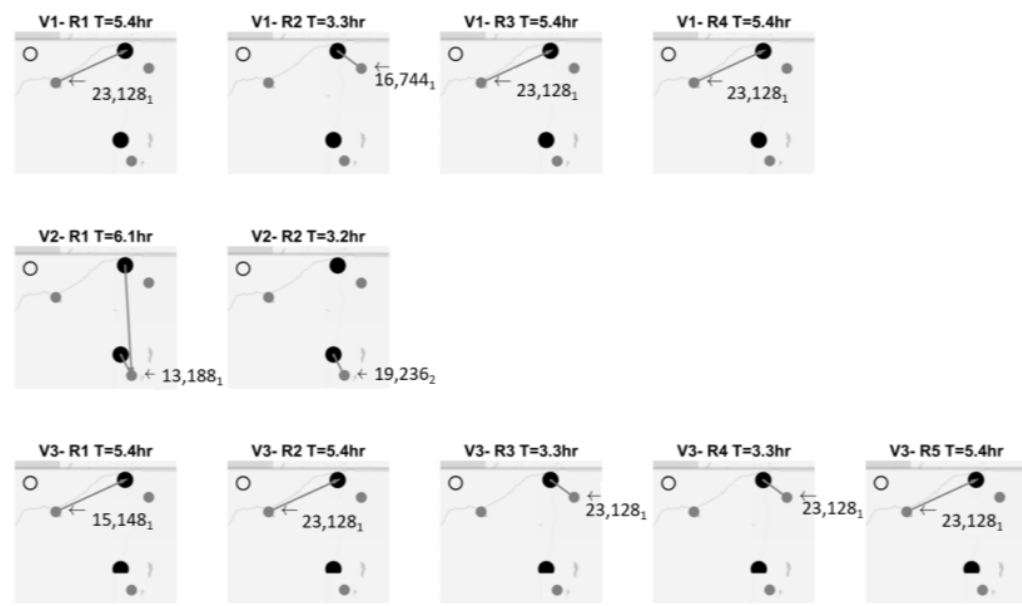

Fig. 3. Transport routes of the solution obtained with the MDMPVRFHFMR model. 
The best fuel price for the customer $\left(S_{j}\right)$ is obtained when using the proposed MDMPVRFHFMR model. It is important to notice that the machine utilization increases when we consider the $M C H$. The unitary costs TRA, VEH and $I N V$ for the three models are compared in Fig. 4. The unitary costs $R A W, M C H$ and the sum of all costs are compared in Fig. 5 for the three models under study.

Although OPEX increases when all costs are minimized, the $M C H$ costs decreases and therefore the total cost is minimized and the best fuel price for the customer $\left(S_{j}\right)$ is obtained.

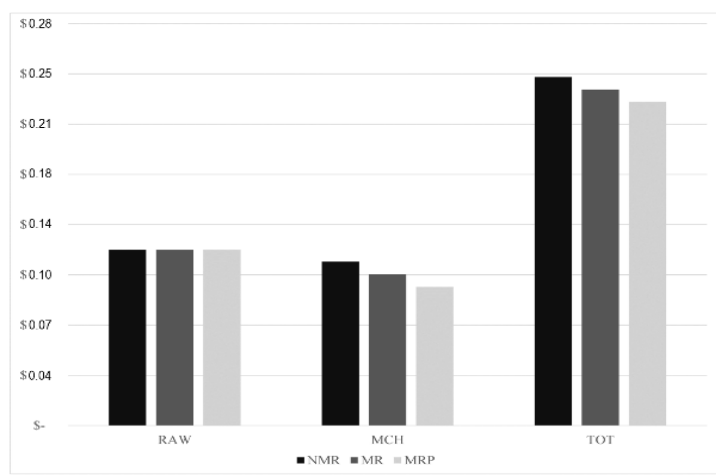

Fig. 4. The $R A W, M C H$ and the total costs for the MDMPVRPHF model.

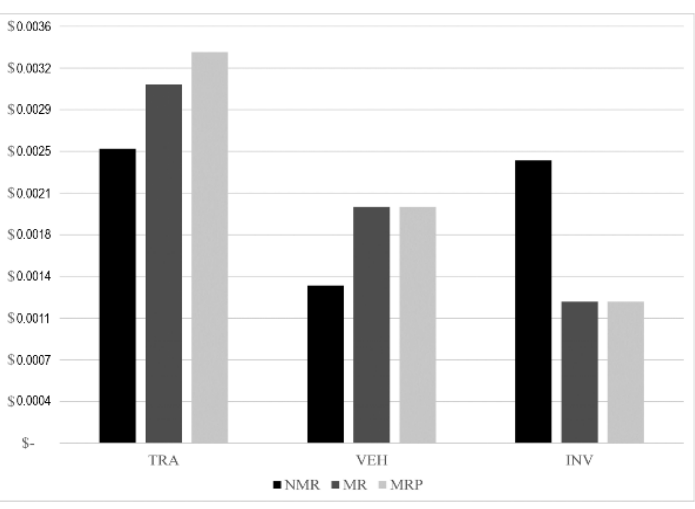

Fig. 5. The TRA, VEH and $V E H$ costs for the MDMPVRPHF model.

\section{COMPUTATIONAL RESULTS}

In this section, we test the performance of the MDMPVRPHF model, the MDMPVRPHFMRWP model, and the MDMPVRPHFMR model. These tests study how suitable the models are to solve small and medium instances. A description of the instances used in the computational study is given in Appendix A. Table 10 shows the computation results for each instance tested.

Table 10. Computation results for each instance.

\begin{tabular}{|c|c|c|c|c|c|c|c|c|c|c|c|c|c|c|c|}
\hline & \multicolumn{5}{|c|}{ MDMPVRPHF } & \multicolumn{5}{|c|}{ MDMPVRPHFMRWP } & \multicolumn{5}{|c|}{ MDMPVRPHFMR } \\
\hline Instance & UB & $\mathrm{LB}$ & $\begin{array}{l}\text { Gap } \\
(\%)\end{array}$ & $\begin{array}{c}\mathrm{CPU} \\
(\mathrm{s})\end{array}$ & $\$ / \mathrm{m} 3$ & UB & $\mathrm{LB}$ & $\begin{array}{l}\text { Gap } \\
(\%)\end{array}$ & $\begin{array}{c}\mathrm{CPU} \\
(\mathrm{s})\end{array}$ & $\$ / \mathrm{m} 3$ & UB & $\mathrm{LB}$ & $\begin{array}{l}\text { Gap } \\
(\%)\end{array}$ & $\begin{array}{c}\mathrm{CPU} \\
(\mathrm{s})\end{array}$ & $\$ / \mathrm{m} 3$ \\
\hline $3 \_10 \_2 \_3$ & 748 & 748 & 0.00 & 145 & 0.2432 & 1005 & 1004 & 0.00 & 374 & 0.2293 & 17836 & 17835 & 0.00 & 52 & 0.2229 \\
\hline 3_15_2_3 & 1012 & 918 & 0.09 & 3604 & 0.2411 & 1229 & 1098 & 0.11 & 3603 & 0.2236 & 25601 & 25545 & 0.00 & 3604 & 0.2236 \\
\hline $3 \_20 \_3 \_3$ & 1460 & 1202 & 0.18 & 3647 & 0.2368 & 1288 & 1012 & 0.21 & 3629 & 0.2279 & 30632 & 30287 & 0.01 & 3675 & 0.2214 \\
\hline 3_25_4_4 & 1357 & 1011 & 0.25 & 3683 & 0.2454 & 1879 & 1236 & 0.34 & 3600 & 0.2346 & - & - & - & $>3600$ & - \\
\hline $4 \_10 \_2 \_3$ & 626 & 626 & 0.00 & 23 & 0.2650 & 968 & 968 & 0.00 & 158 & 0.2471 & 15679 & 15678 & 0.00 & 214 & 0.2379 \\
\hline $4 \_15 \_2 \_3$ & 894 & 865 & 0.03 & 3603 & 0.2300 & 1168 & 1065 & 0.09 & 3618 & 0.2325 & 24793 & 24649 & 0.01 & 3609 & 0.2218 \\
\hline $4 \_20 \_3 \_3$ & 1154 & 1019 & 0.12 & 3615 & 0.2325 & 1621 & 1209 & 0.25 & 3932 & 0.2282 & 30340 & 30033 & 0.01 & 3601 & 0.2168 \\
\hline $4 \_25 \_4 \_4$ & 1524 & 1016 & 0.33 & 3605 & 0.2389 & - & - & - & $>3600$ & - & - & - & - & $>3600$ & - \\
\hline $5 \_10 \_2 \_3$ & 754 & 754 & 0.00 & 136 & 0.2539 & 983 & 983 & 0.00 & 54 & 0.2521 & 15624 & 15622 & 0.00 & 58 & 0.2400 \\
\hline $5 \_15 \_2 \_3$ & 909 & 855 & 0.06 & 3605 & 0.2393 & 1206 & 1051 & 0.13 & 3607 & 0.2286 & 22473 & 22408 & 0.00 & 3604 & 0.2146 \\
\hline $5 \_20 \_3 \_3$ & 1264 & 1091 & 0.14 & 3628 & 0.2464 & 1644 & 1294 & 0.21 & 3653 & 0.2289 & 31040 & 30842 & 0.01 & 3645 & 0.2146 \\
\hline 5_25_4 4 4 & - & - & - & $>3600$ & - & - & - & - & $>3600$ & - & - & - & - & $>3600$ & - \\
\hline
\end{tabular}


Fig. 6 shows the relative gap between the upper and lower bounds. Here, it is possible to conclude that the MDMPVRPHFMR model achieves the lowest relative gap in the same amount of computing time. For solving the MDMPVRPHFMRWP, the relative gap increases probably because the MDMPVRPHF does not narrow the possible best solutions. In the case of the MDMPVRPHFMR model, OPEX and CAPEX narrows the feasible solutions region.

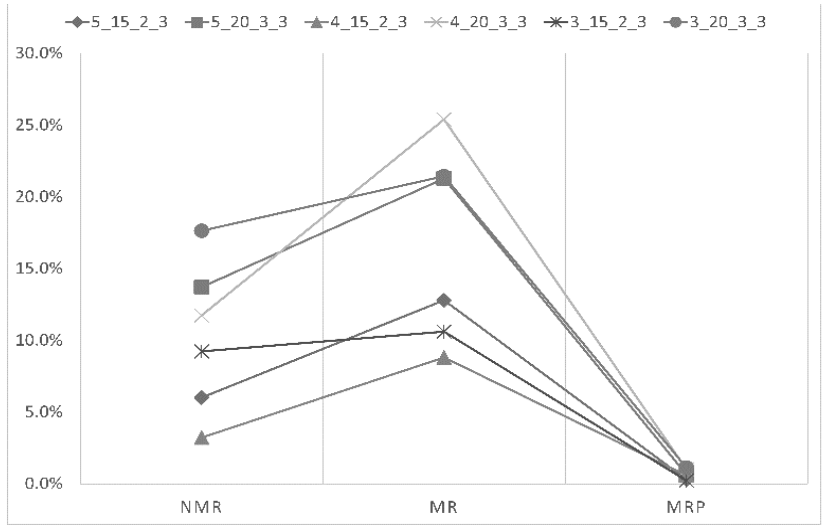

Fig. 6. Relative gap for instances with 15 and 20 demand points.

Fig. 7 shows the LNG fuel prices achieved with the MDMPVRPHF model, the MDMPVRPHFMRWP model and the MDMPVRPHFMR model. The LNG fuel price are minimized for all instances when using the MDMPVRPHFMR model. Therefore, we can conclude that companies must consider CAPEX and OPEX for designing their supply chain networks when the contract period is fixed between the supplier and the customer.

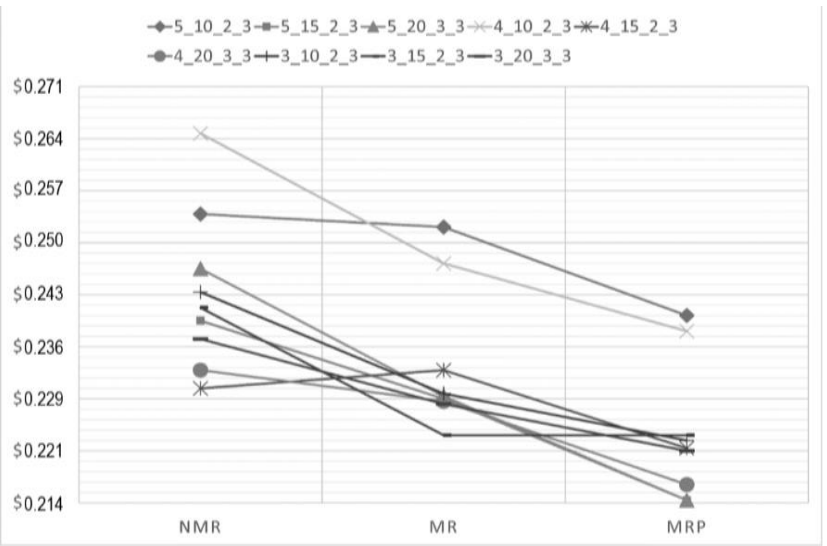

Fig. 7. Fuel cost for instances with 10, 15 and 20 demand points.

\section{CONCLUSIONS AND FUTURE WORK}

The Multi Depot Multi Period Vehicle Routing Problem with heterogeneous fleet and management restrictions (MDMPVRPHFMR) has been introduced and formulated in this paper. This is a modification of Mancini (2016) Multi Depot Multi Period Vehicle Routing Problem with heterogeneous fleet (MDMPVRPHF) to consider capital expenditures and operating expenses (MDMPVRPHFMR). In the MDMPVRPHFMR, the goal is to carry out delivery operations at the minimum costs by considering transport costs, vehicle rent costs, time services, raw material, investments, and machine costs. In this paper, we test the proposed MDMPVRPHFMR model and the MDMPVRPHF model in a real case scenario and by solving different instances with random parameters to test the effectiveness and efficacy of these models. The results allows to compare the performance of the proposed MDMPVRPHFMR model with the results obtained using the model proposed by Mancini (2016) or MDMPVRPHF model. By comparing results, it is possible to conclude that the minimum total cost, and hence the minimum fuel price $\left(S_{j}\right)$, is reached when using the MDMPVRFHFMR model. The results indicates that CAPEX and OPEX must be considered. It also demonstrates that the model proposed by Mancini (2016) (the MDMPVRFHFMR model) does not achieve the lowest possible cost in a real company scenario.

The major contribution of this paper is the proposition of a model capable of minimizing CAPEX and OPEX at the same time with the aim of designing a LNG supply chain network considering must of the variables presented in a real company scenario. By considering more variables and having more real restrictions the feasible solutions region is narrowed and therefore the relative gap between the upper and lower bound is reduced. Finally, it is possible to conclude that companies must consider CAPEX and OPEX for designing real supply chain networks when the contract period is fixed between the supplier and the customer.

As future work, a Periodic Multi Period Vehicle Routing Problem with heterogeneous fleet and management restrictions can be developed for companies that require periodic deliveries. Such a model can be an extension of the periodic vehicle routing problem 


\section{APPENDIX A.}

All instances have the parameters shown in Table A.1.

Table A.1. Fixed parameters for all instances.

\begin{tabular}{|c|c|c|c|}
\hline Description & Variable & Value & Unit \\
\hline Contract period & - & 7 & [year] \\
\hline Maximum route duration & $\alpha$ & 24 & {$[\mathrm{~h}]$} \\
\hline Vehicles average speed & $s$ & 50 & {$[\mathrm{~km} / \mathrm{h}]$} \\
\hline Planning time horizon & $\Theta$ & 24 & {$[\mathrm{~h}]$} \\
\hline Transport capacity per vehicle & $C^{v}$ & 23,128 & {$[\mathrm{~m} 3]$} \\
\hline Cost of usage per vehicle & $\mu^{v}$ & 0.50 & {$[\$ / \mathrm{km}]$} \\
\hline Machine cost & $p^{m}$ & $\$ 1,447.70$ & {$[\$ /$ day $]$} \\
\hline Production capacity of machine & $c^{m}$ & 20,720 & {$[\mathrm{~m} 3 /$ day $]$} \\
\hline Time to discharge/charge material & $\delta_{i}$ & 60 & {$[\mathrm{~h}]$} \\
\hline Penalty cost in visit times & $\gamma$ & 20 & {$[\$]$} \\
\hline Cost of renting/buying the vehicle & $\beta$ & 150 & {$[\$ /$ day $]$} \\
\hline
\end{tabular}

Instance $3 \_10 \_2 \_3$ :

Table A.2. General information of instance

\begin{tabular}{clll}
\hline Description & Variable & Value & Unit \\
\hline No. of possible supply stations & $\mathrm{I}$ & 3 & {$[-]$} \\
No. of demand locations & $D$ & 10 & {$[-]$} \\
No. of vehicles & $V$ & 2 & {$[-]$} \\
No. of routes & $\mathrm{K}$ & 3 & {$[-]$} \\
No. of machines & $M$ & 1 & {$[-]$} \\
\hline
\end{tabular}

Table A.3. Daily demand, opening costs and raw material cost of instance.

\begin{tabular}{lllll}
\hline Location & $\begin{array}{l}\text { Demand } \\
{[\mathbf{m 3} / \text { day }]}\end{array}$ & $\begin{array}{l}\text { Supply } \\
\text { Station }\end{array}$ & $\begin{array}{l}\text { Opening cost } \\
{[\$ / \text { day }]}\end{array}$ & $\begin{array}{l}\text { Raw material } \\
\text { cost }[\$ / \mathbf{m 3}]\end{array}$ \\
\hline C_1 & 11,760 & SS_1 & 195.69 & 0.1464 \\
C_2 & 3,500 & SS_2 & 195.69 & 0.1429 \\
C_3 & 6,776 & SS_3 & 195.69 & 0.1393 \\
C_4 & 10,332 & & & \\
C_5 & 11,480 & & & \\
C_6 & 1,624 & & & \\
C_7 & 13,468 & & & \\
C_8 & 10,024 & & & \\
C_9 & 3,892 & & \\
C_10 & 6,076 & & \\
\hline
\end{tabular}




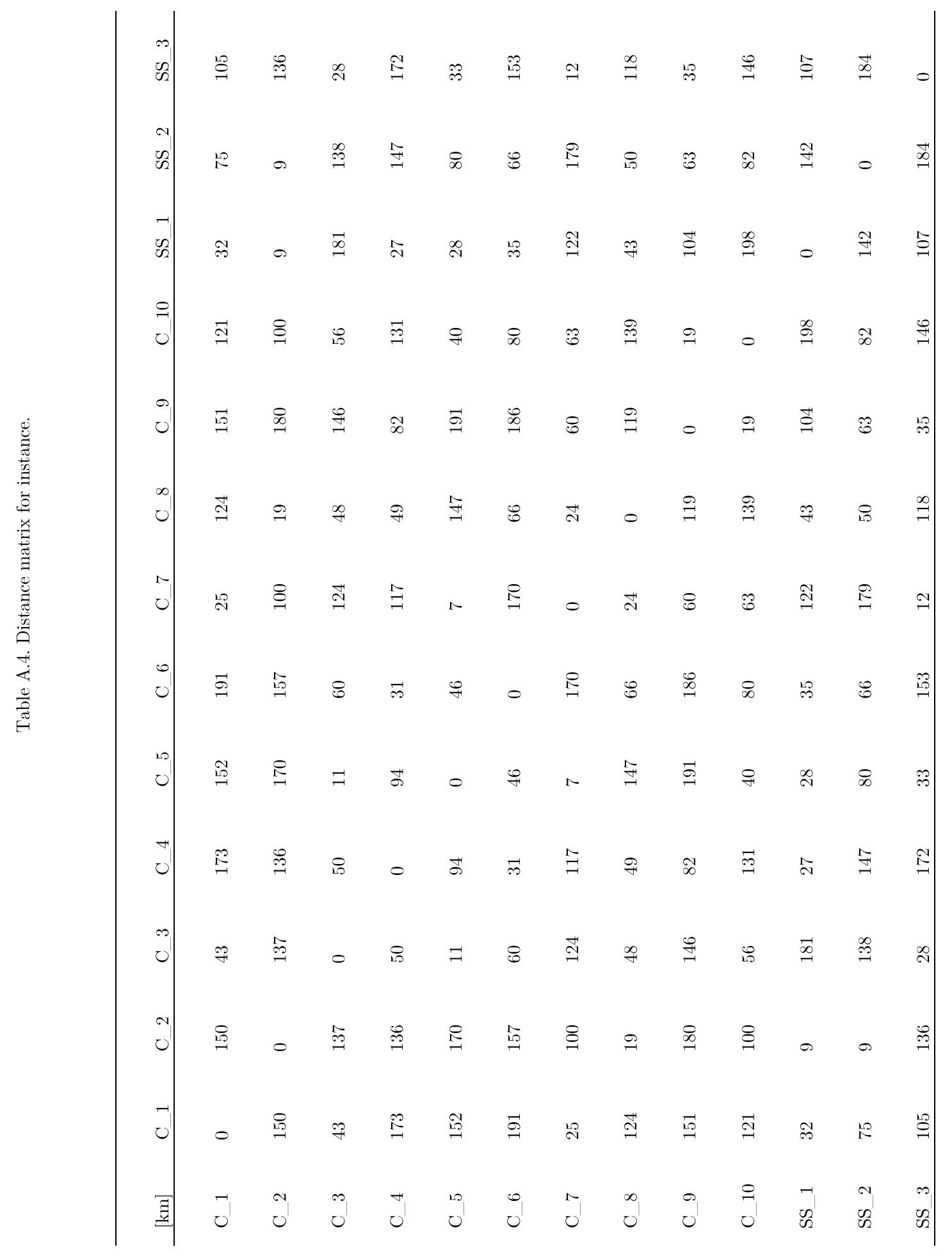


Instance $3 \_15 \_2 \_3$ :

Table A.5. General information of instance.

\begin{tabular}{cccc}
\hline Description & Variable & Value & Unit \\
\hline No. of possible supply stations & I & 3 & {$[-]$} \\
No. of demand locations & $D$ & 15 & {$[-]$} \\
No. of vehicles & $V$ & 2 & {$[-]$} \\
No. of routes & K & 3 & {$[-]$} \\
No. of machines & $M$ & 1 & {$[-]$} \\
\hline
\end{tabular}

Table A.6. Daily demand, opening costs and raw material cost of instance.

\begin{tabular}{ccccc}
\hline Location & $\begin{array}{c}\text { Demand } \\
{[\mathrm{m} 3 / \text { day }]}\end{array}$ & $\begin{array}{c}\text { Supply } \\
\text { Station }\end{array}$ & $\begin{array}{c}\text { Opening cost } \\
{[\$ / \text { day }]}\end{array}$ & $\begin{array}{c}\text { Raw material } \\
\text { cost }[\$ / \mathbf{m 3}]\end{array}$ \\
\hline C_1 & 11,760 & SS_1 & 195.69 & 0.1464 \\
C_2 & 2,688 & SS_2 & 195.69 & 0.1429 \\
C_3 & 3,388 & SS_3 & 195.69 & 0.1393 \\
C_4 & 6,776 & & & \\
C_5 & 10,332 & & & \\
C_6 & 3,108 & & & \\
C_7 & 13,020 & & & \\
C_8 & 7,532 & & & \\
C_9 & 11,480 & & & \\
C_10 & 1,624 & & & \\
C_11 & 7,448 & & & \\
C_12 & 13,468 & & & \\
C_13 & 10,024 & & & \\
C_14 & 3,892 & & & \\
C_15 & 6,076 & & \\
\hline
\end{tabular}




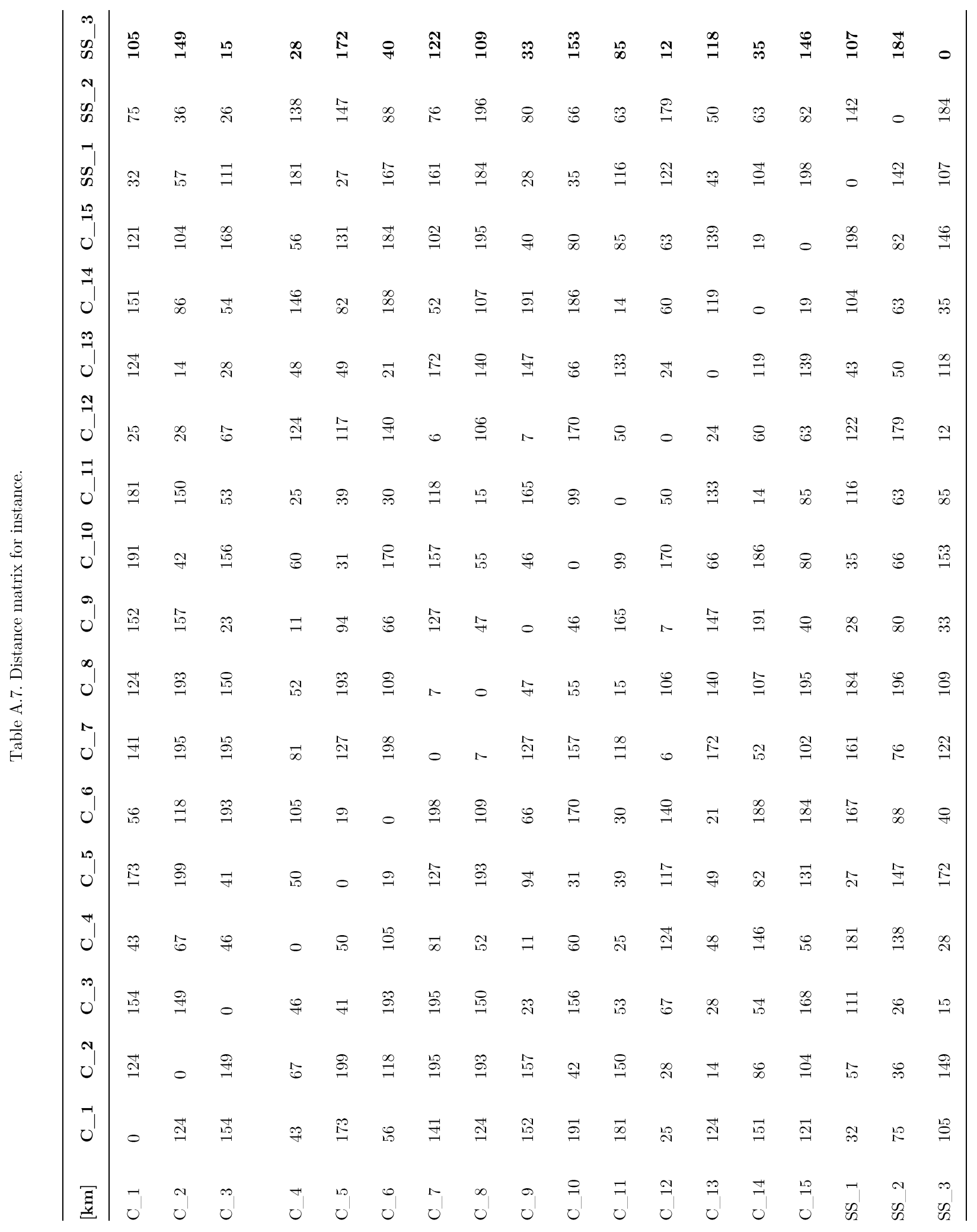


Instance $3 \_20 \_3 \_3$ :

Table A.8. General information of instance.

\begin{tabular}{llll}
\hline Description & Variable & Value & Unit \\
\hline No. of possible supply stations & I & 3 & {$[-]$} \\
No. of demand locations & $D$ & 20 & {$[-]$} \\
No. of vehicles & $V$ & 3 & {$[-]$} \\
No. of routes & $\mathrm{K}$ & 3 & {$[-]$} \\
No. of machines & $M$ & 1 & {$[-]$} \\
\hline
\end{tabular}

Table A.9. Daily demand, opening costs and raw material cost of instance.

\begin{tabular}{lllll}
\hline Location & $\begin{array}{l}\text { Demand } \\
{[\mathrm{m} 3 / \text { day }]}\end{array}$ & $\begin{array}{l}\text { Supply } \\
\text { Station }\end{array}$ & $\begin{array}{l}\text { Opening } \\
{[\$ / \text { day }]}\end{array}$ & $\begin{array}{l}\text { cost } \\
{[\$ / \mathbf{m} 3]}\end{array}$ \\
\hline C_1 & 11,760 & SS_1 & 195.69 & 0.1464 \\
C_2 & 9,184 & SS_2 & 195.69 & 0.1429 \\
C_3 & 2,688 & SS_3 & 195.69 & 0.1393 \\
C_4 & 3,388 & & & \\
C_5 & 1,624 & & & \\
C_6 & 3,500 & & & \\
C_7 & 6,776 & & & \\
C_8 & 10,332 & & & \\
C_9 & 3,108 & & & \\
C_10 & 13,020 & & & \\
C_11 & 7,532 & & & \\
C_12 & 11,480 & & & \\
C_13 & 2,492 & & \\
C_14 & 6,468 & & \\
C_15 & 1,624 & & \\
C_16 & 7,448 & & \\
C_17 & 13,468 & & \\
C_18 & 10,024 & & \\
C_19 & 3,892 & & \\
C_20 & 6,076 & & \\
\hline
\end{tabular}




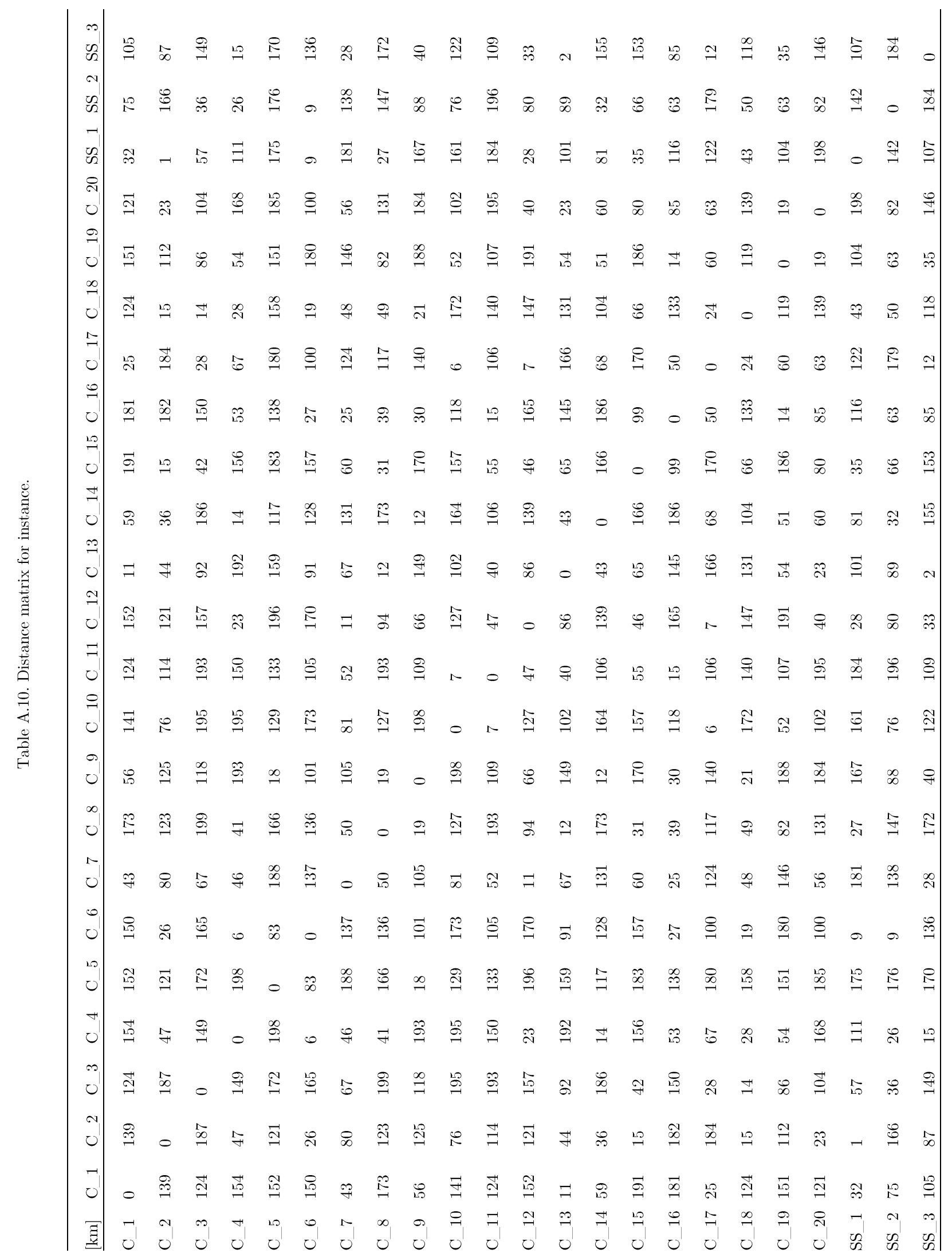


Instance 3_25_4_4:

Table A.11. General information of instance.

\begin{tabular}{llll}
\hline Description & Variable & Value & Unit \\
\hline No. of possible supply stations & $\mathrm{I}$ & 3 & {$[-]$} \\
No. of demand locations & $D$ & 25 & {$[-]$} \\
No. of vehicles & $V$ & 4 & {$[-]$} \\
No. of routes & $\mathrm{K}$ & 4 & {$[-]$} \\
No. of machines & $M$ & 1 & {$[-]$} \\
\hline
\end{tabular}

Table A.12. Daily demand, opening costs and raw material cost of instance.

\begin{tabular}{|c|c|c|c|c|}
\hline Location & $\begin{array}{l}\text { Demand } \\
{[\mathrm{m} 3 / \text { day }]}\end{array}$ & $\begin{array}{l}\text { Supply } \\
\text { Station }\end{array}$ & $\begin{array}{l}\text { Opening cost } \\
{[\$ / \text { day }]}\end{array}$ & $\begin{array}{l}\text { Raw material } \\
\text { cost }[\$ / \mathrm{m} 3]\end{array}$ \\
\hline C_1 & 2,352 & SS_1 & 195.69 & 0.1464 \\
\hline C_2 & 5,880 & SS_2 & 195.69 & 0.1429 \\
\hline C__3 & 1,484 & SS $\_3$ & 195.69 & 0.1393 \\
\hline C__ 4 & 4,424 & & & \\
\hline C_5 & 10,220 & & & \\
\hline C_6 & 3,500 & & & \\
\hline C_-7 & 1,876 & & & \\
\hline C_8 & 6,244 & & & \\
\hline C_9 & 1,624 & & & \\
\hline C_10 & 7,448 & & & \\
\hline C_11 & 4,424 & & & \\
\hline C_12 & 9,492 & & & \\
\hline C_13 & 1,624 & & & \\
\hline C_14 & 7,448 & & & \\
\hline C_15 & 5,264 & & & \\
\hline C_16 & 952 & & & \\
\hline C_17 & 7,588 & & & \\
\hline C_18 & 3,948 & & & \\
\hline C_19 & 6,748 & & & \\
\hline C_20 & 9,604 & & & \\
\hline C_21 & 2,940 & & & \\
\hline C_22 & 8,540 & & & \\
\hline C_23 & 4,592 & & & \\
\hline C_24 & 7,168 & & & \\
\hline C_25 & 1,876 & & & \\
\hline
\end{tabular}




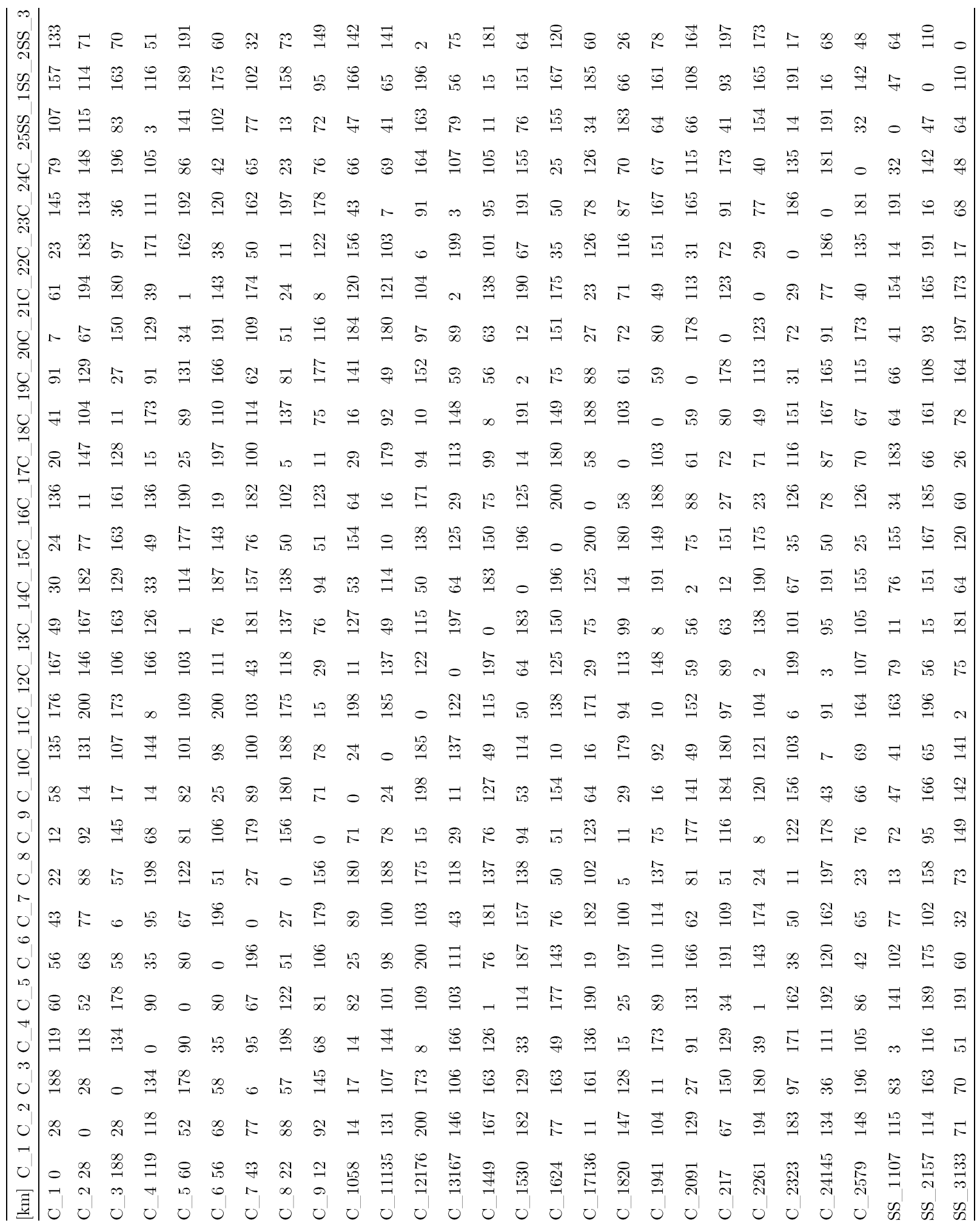


Instance $4 \_10 \_2 \_3$ :

Table A.14. General information of instance.

\begin{tabular}{llll}
\hline Description & Variable & Value & Unit \\
\hline No. of possible supply stations & I & 4 & {$[-]$} \\
No. of demand locations & $D$ & 10 & {$[-]$} \\
No. of vehicles & $V$ & 2 & {$[-]$} \\
No. of routes & $\mathrm{K}$ & 3 & {$[-]$} \\
No. of machines & $M$ & 1 & {$[-]$} \\
\hline
\end{tabular}

Table A.15. Daily demand, opening costs and raw material cost of instance.

\begin{tabular}{llllll}
\hline Location & $\begin{array}{l}\text { Demand } \\
{[\mathrm{m3} / \mathrm{day}]}\end{array}$ & $\begin{array}{l}\text { Supply } \\
\text { Station }\end{array}$ & $\begin{array}{l}\text { Opening } \\
{[\$ / \text { day }]}\end{array}$ & cost & $\begin{array}{l}\text { Raw material cost } \\
{[\$ / \mathrm{m} 3]}\end{array}$ \\
\hline C_1 & 3,388 & SS_1 & 195.69 & 0.1357 \\
C_2 & 13,020 & SS_2 & 195.69 & 0.1393 \\
C_3 & 2,492 & SS_3 & 195.69 & 0.1429 \\
C_4 & 6,468 & SS_4 & 195.69 & 0.1464 \\
C_5 & 1,624 & & & \\
C_6 & 4,424 & & & \\
C_7 & 13,468 & & & \\
C_8 & 10,024 & & & \\
C_9 & 3,892 & & \\
C_10 & 6,076 & & \\
\hline
\end{tabular}




\begin{tabular}{|c|c|c|c|c|c|c|c|c|c|c|c|c|c|c|}
\hline in & $\stackrel{12}{\rightarrow}$ & స̃ & N & 点 & 量 & $\stackrel{10}{\infty}$ & ㄱ & $\stackrel{\infty}{=}$ & م. & $\stackrel{\stackrel{\leftrightarrow}{H}}{\sim}$ & 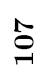 & $\stackrel{\vec{\infty}}{\rightarrow}$ & 冷 & 0 \\
\hline $\begin{array}{l}1 \\
\text { on }\end{array}$ & $\stackrel{P}{\rightarrow}$ & வ゙ & ĩ & $\stackrel{\infty}{\stackrel{\infty}{\sim}}$ & ठ゙ & 5 & $\stackrel{\Lambda}{\infty}$ & $\underset{\exists}{\exists}$ & $\vec{\infty}$ & 今o & $\underset{N}{\stackrel{N}{\sim}}$ & 19 & 0 & 总 \\
\hline $\begin{array}{l}1 \\
\text { on }\end{array}$ & $\stackrel{\sim}{*}$ & $i$ & $\infty$ & $\therefore$ & 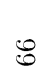 & 8 & 尺 & 8 & : & $\mathscr{\infty}$ & $\underset{\mathcal{F}}{\exists}$ & 0 & 19 & $\stackrel{+\infty}{\rightarrow+}$ \\
\hline on & $\exists$ & $\vec{\sigma}$ & $\vec{\Xi}$ & $\vec{\infty}$ & 骂 & $\stackrel{\varrho}{=}$ & 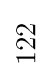 & $\stackrel{9}{*}$ & 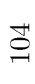 & $\stackrel{\infty}{g}$ & 0 & $\mathcal{F}$ & $\stackrel{\mathcal{N}}{\underline{N}}$ & $\stackrel{\hat{\varrho}}{=}$ \\
\hline 'ا & $\stackrel{\infty}{\Theta}$ & $\tilde{\vartheta}$ & $\stackrel{9}{\Im}$ & 8 & $\infty$ & 18 & 8 & 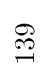 & $\stackrel{\vartheta}{-}$ & 0 & $\stackrel{\infty}{\stackrel{9}{\rightarrow}}$ & $\tilde{\infty}$ & $\hat{s}$ & $\stackrel{\mathscr{I}}{I}$ \\
\hline $\begin{array}{l}\theta_{1} \\
u^{\prime}\end{array}$ & 落 & 동 & 落 & $\vec{b}$ & $\stackrel{\infty}{\rightarrow}$ & 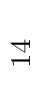 & 8 & $\stackrel{\Xi}{=}$ & 0 & $\stackrel{2}{7}$ & $\stackrel{\vec{\sigma}}{=}$ & 8 & $\vec{\infty}$ & $\therefore$ \\
\hline $\begin{array}{l}\infty \\
0 \\
0\end{array}$ & $\stackrel{\infty}{\sim}$ & $\stackrel{\mathbb{N}}{\underline{N}}$ & $\overrightarrow{9}$ & $\stackrel{\vec{\leftrightarrows}}{\leftrightarrows}$ & $\because$ & $\stackrel{\leftrightarrow}{\stackrel{9}{\rightarrow}}$ & $\stackrel{N}{N}$ & 0 & $\stackrel{\Theta}{=}$ & 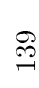 & $\stackrel{9}{9}$ & 85 & $\underset{\exists}{-}$ & $\stackrel{\infty}{=}$ \\
\hline 'آ & $\hat{0}$ & 0 & $\because$ & $\ddot{\theta}$ & R & 8 & 0 & $\vec{N}$ & 8 & 8 & ָ̃ & $\stackrel{\Omega}{2}$ & $\infty$ & $\stackrel{1}{f}$ \\
\hline إن & is & $\stackrel{\infty}{=}$ & $\stackrel{\text { 哭 }}{9}$ & $\stackrel{\infty}{\infty}$ & 8 & 0 & 88 & 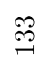 & $\mathbb{Z}$ & 190 & 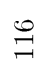 & 83 & $\vec{B}$ & $\mathscr{\infty}$ \\
\hline $\begin{array}{l}\text { إ } \\
\end{array}$ & $\stackrel{\leftrightarrow}{\stackrel{\leftrightarrow}{n}}$ & $\stackrel{\text { 点 }}{\rightarrow}$ & 18 & $\stackrel{\bullet}{\bullet}$ & 0 & 8 & R & $\because$ & $\underset{\infty}{\infty}$ & $\infty$ & $\stackrel{80}{\circ}$ & $\notin$ & ठే & 渴 \\
\hline $\begin{array}{l}\vec{J}^{\prime} \\
\end{array}$ & 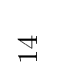 & 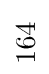 & $\stackrel{9}{\Im}$ & 0 & $\stackrel{\bullet}{\mathscr{G}}$ & $\stackrel{\infty}{\infty}$ & 98 & 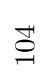 & 5 & 8 & $\vec{\infty}$ & กิ & $\stackrel{\infty}{\infty}$ & 哥 \\
\hline $\begin{array}{l}\text { la } \\
\\
\end{array}$ & $\stackrel{\Im}{g}$ & 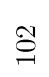 & 0 & $\stackrel{9}{*}$ & 18 & $\stackrel{2}{9}$ & 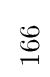 & $\vec{\Omega}$ & 吾 & $\stackrel{\curvearrowright}{\sim}$ & $\stackrel{\Xi}{\sigma}$ & $\not \infty$ & 용 & 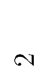 \\
\hline $\begin{array}{l}N_{1} \\
0\end{array}$ & $\stackrel{\mathscr{g}}{9}$ & 0 & $\stackrel{\widetilde{O}}{\sigma}$ & $\underset{త}{\mathbb{U}}$ & 点 & $\stackrel{\infty}{=}$ & 0 & $\stackrel{\mathbb{N}}{\underline{N}}$ & ำ & $\stackrel{\mathcal{O}}{\mathcal{O}}$ & $\overrightarrow{0}$ & $\stackrel{R}{i}$ & $\rightleftarrows$ & స్ \\
\hline 'إ & 0 & $\stackrel{\text { 足 }}{9}$ & $\tilde{\mathcal{G}}$ & $\exists$ & $\stackrel{\mathscr{L}}{\rightarrow}$ & $\stackrel{i b}{i}$ & 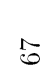 & $\stackrel{\infty}{\sim}$ & 出 & $\stackrel{\infty}{0}$ & $\exists$ & $\stackrel{\sim}{\sim}$ & $\stackrel{9}{\rightarrow}$ & $\stackrel{12}{=}$ \\
\hline $\bar{z}$ & & $v_{\nu}$ & $\leadsto$ & + & 10 & 0 & 1 & $\infty$ & 3 & $\stackrel{\ominus}{\sim}$ & $\rightarrow$ & 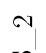 & $\infty$ & 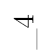 \\
\hline$\underline{z}$ & O & O & ' & 0 & U & ' & U & 0 & 0 & 0 & $\frac{w}{n}$ & w & $\frac{w}{n}$ & w \\
\hline
\end{tabular}


Instance 4_15_2_3:

Table A.17. General information of instance.

\begin{tabular}{llll}
\hline Description & Variable & Value & Unit \\
\hline No. of possible supply stations & $\mathrm{I}$ & 4 & {$[-]$} \\
No. of demand locations & $D$ & 15 & {$[-]$} \\
No. of vehicles & $V$ & 2 & {$[-]$} \\
No. of routes & $\mathrm{K}$ & 3 & {$[-]$} \\
No. of machines & $M$ & 1 & {$[-]$} \\
\hline
\end{tabular}

Table A.18. Daily demand, opening costs and raw material cost of instance.

\begin{tabular}{lllll}
\hline Location & $\begin{array}{l}\text { Demand } \\
{[\mathbf{m 3} / \text { day }]}\end{array}$ & $\begin{array}{l}\text { Supply } \\
\text { Station }\end{array}$ & $\begin{array}{l}\text { Opening } \\
{[\$ / \text { day }]}\end{array}$ & $\begin{array}{l}\text { cost } \\
\text { Raw } \\
\text { material cost }\end{array}$ \\
\hline C_1 & 11,844 & SS_1 & 195.69 & 0.1357 \\
C_2 & 3,388 & SS_2 & 195.69 & 0.1393 \\
C_3 & 7,168 & SS_3 & 195.69 & 0.1429 \\
C_4 & 6,776 & SS_4 & 195.69 & 0.1464 \\
C_5 & 13,020 & & & \\
C_6 & 7,532 & & & \\
C_7 & 11,480 & & & \\
C_8 & 2,492 & & \\
C_9 & 6,468 & & \\
C_10 & 1,624 & & \\
C_11 & 4,424 & & \\
C_12 & 13,468 & & \\
C_13 & 10,024 & & \\
C_14 & 3,892 & & \\
C_15 & 6,076 & & \\
\hline
\end{tabular}




\begin{tabular}{|c|c|c|c|c|c|c|c|c|c|c|c|c|c|c|c|c|c|c|c|}
\hline in & $\infty$ & $\stackrel{10}{-1}$ & $\stackrel{\oplus}{\rightarrow}$ & $\stackrel{\infty}{N}$ & ָ̃ & $\stackrel{8}{\stackrel{9}{-1}}$ & ๓̊ & N & $\begin{array}{l}\text { 量 } \\
\text { 至 }\end{array}$ & 总 & $\infty$ & $\mathcal{F}$ & $\stackrel{\infty}{=}$ & 足 & $\stackrel{\mathscr{I}}{\sim}$ & 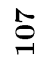 & $\infty$ & 昰 & 0 \\
\hline o & 点 & $\stackrel{9}{\rightarrow}$ & $\mathcal{\exists}$ & 듬 & $\Phi_{\infty}$ & $\mathfrak{i}$ & $\stackrel{\infty}{\circ}$ & ำ & $\stackrel{\infty}{\infty}$ & ठే & 5 & $\stackrel{\infty}{\infty}$ & $\exists$ & $\vec{\infty}$ & $\widehat{s}$ & $\stackrel{\mathbb{N}}{\underset{N}{*}}$ & 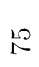 & 0 & 昰 \\
\hline$\tilde{\Omega}$ & $\stackrel{8}{:}$ & $\stackrel{\mathscr{N}}{\sim}$ & 0 & $\stackrel{\infty}{\oplus}$ & $\stackrel{R}{2}$ & $\stackrel{\mathscr{S}}{\mathscr{G}}$ & $\infty$ & $\infty$ & $\therefore$ & $\because$ & 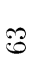 & $\stackrel{8}{2}$ & 吕 & 8 & $\infty$ & $\mathfrak{F}$ & b & $\stackrel{18}{2}$ & $\underset{\sim}{\stackrel{0}{\sim}}$ \\
\hline of & -1 & $\exists$ & 0 & $\stackrel{\vec{\infty}}{\sim}$ & $\vec{\sigma}$ & $\stackrel{\vec{\infty}}{=}$ & $\stackrel{\infty}{\sim}$ & $\stackrel{\vec{g}}{ }$ & $\vec{\infty}$ & 19 & $\stackrel{\Xi}{=}$ & Iิ & $\stackrel{P}{P}$ & $\stackrel{\oplus}{9}$ & $\stackrel{\infty}{\stackrel{\leftrightarrow}{\rightarrow}}$ & 0 & $\underset{I}{I}$ & $\stackrel{\mathbb{N}}{\mathbb{N}}$ & $\stackrel{Ð}{\circ}$ \\
\hline |' & $\stackrel{\sim}{\sim}$ & 象 & $\underset{\sim}{\stackrel{ }{~}}$ & $\stackrel{8}{\circ}$ & 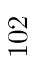 & 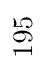 & f & 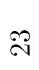 & 8 & $\varnothing$ & $\infty$ & $\because$ & 宛 & $\stackrel{2}{-}$ & 0 & $\stackrel{\infty}{\stackrel{\circ}{\sim}}$ & $\tilde{\infty}$ & $\widehat{\hat{\rho}}$ & $\underset{\sim}{\mathbb{I}}$ \\
\hline |' & $\mathcal{F}$ & $\vec{B}$ & $\stackrel{\infty}{\rightarrow}$ & $\stackrel{\mathscr{H}}{\sim}$ & Iี & 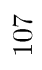 & $\vec{\Omega}$ & 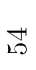 & 5 & $\stackrel{\infty}{\rightarrow}$ & $\mathbb{Z}$ & 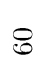 & $\stackrel{g}{\exists}$ & 0 & $\stackrel{9}{\rightarrow}$ & 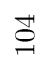 & 3 & $\vec{\infty}$ & 品 \\
\hline 'إ & $\stackrel{20}{\longrightarrow}$ & $\stackrel{\infty}{N}$ & $\stackrel{\theta}{2}$ & $\stackrel{\infty}{\rightarrow+}$ & $\stackrel{N}{\Sigma}$ & $\underset{\sim}{\stackrel{O}{7}}$ & 年 & 9 & $\underset{\ominus}{\stackrel{*}{*}}$ & 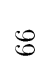 & 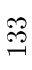 & $\stackrel{\sim}{N}$ & 0 & $\exists$ & 祖 & $\stackrel{9}{F}$ & 8 & $\exists$ & $\stackrel{\infty}{=}$ \\
\hline |' & $\stackrel{\rightleftarrows}{-\infty}$ & $\hat{\jmath}$ & $\S$ & $\stackrel{\Xi}{-}$ & 0 & $\stackrel{\Xi}{\mathscr{G}}$ & $\Lambda$ & 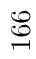 & $\stackrel{\infty}{\circ}$ & 尺 & 8 & 0 & $\stackrel{J}{J}$ & 8 & 8 & సิ & I & ద & 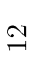 \\
\hline 'ان & $\underset{\infty}{\tilde{D}}$ & 涫 & ล & $\stackrel{2}{N}$ & $\stackrel{\infty}{=}$ & $\stackrel{2}{\longrightarrow}$ & $\stackrel{8}{\stackrel{8}{\circ}}$ & $\stackrel{\text { 㝵 }}{-}$ & $\stackrel{\infty}{\infty}$ & 8 & 0 & 8 & 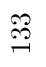 & 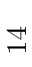 & $\mathscr{\infty}$ & $\stackrel{\varrho}{\exists}$ & 83 & 15 & $\mathscr{\infty}$ \\
\hline |' & $\stackrel{20}{\sim}$ & 总 & 点 & $\mathscr{0}$ & 总 & 18 & $\mathscr{f}$ & 18 & 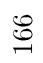 & 0 & $\mathscr{8}$ & $\stackrel{R}{T}$ & 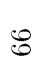 & $\underset{\sim}{\infty}$ & $\infty$ & $\therefore 8$ & $\stackrel{8}{8}$ & s & 渴 \\
\hline 'ان & $\ddot{\circ}$ & 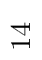 & $\stackrel{\infty}{\underset{J}{\sim}}$ & $\overrightarrow{\text { ș }}$ & త્తٍ & 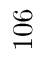 & 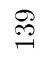 & $\stackrel{?}{q}$ & 0 & 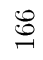 & $\underset{\sim}{\infty}$ & $\stackrel{\infty}{\circ}$ & 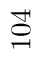 & E) & 8 & $\vec{\infty}$ & ถิ & 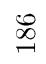 & 昜 \\
\hline | & $\not{F}$ & $\stackrel{\widetilde{S}}{\vec{G}}$ & $\vec{\sigma}$ & $\hat{\sigma}$ & 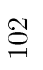 & \& & $\infty$ & 0 & $\stackrel{9}{q}$ & 18 & 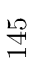 & $\stackrel{\leftrightarrow}{\leftrightarrow}$ & $\overrightarrow{9}$ & to & $\stackrel{2}{\sim}$ & $\stackrel{\Xi}{\sigma}$ & 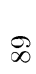 & iv & N \\
\hline 'ان & $\vec{I}$ & $\stackrel{\text { s }}{\text { s }}$ & 尺 & $\exists$ & $\stackrel{\mathfrak{J}}{\Im}$ & 年 & 0 & 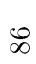 & 吕 & $\stackrel{f}{q}$ & 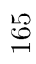 & N & 年 & 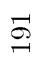 & f & $\stackrel{\infty}{N}$ & $\nexists$ & $\stackrel{\infty}{\infty}$ & $\because$ \\
\hline | & $\underset{\exists}{\exists}$ & $\stackrel{8}{\stackrel{8}{\rightarrow}}$ & $\stackrel{8}{\stackrel{9}{\circ}}$ & ชี & $n$ & 0 & 年 & F & 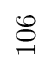 & 19 & $\stackrel{29}{9}$ & 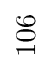 & $\underset{\sim}{\stackrel{O}{\prime}}$ & $\stackrel{1}{\circ}$ & $\stackrel{\mathscr{g}}{9}$ & $\underset{\infty}{\stackrel{\infty}{~}}$ & $\stackrel{\leftrightarrow}{2}$ & $\Re$ & $\stackrel{8}{\stackrel{2}{0}}$ \\
\hline أ & $\stackrel{p}{1}$ & $\stackrel{\text { 昌 }}{9}$ & $\stackrel{\Re}{=}$ & $\vec{\infty}$ & 0 & $\Lambda$ & $\stackrel{\mathfrak{N}}{\mathrm{N}}$ & $\stackrel{8}{\circ}$ & 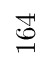 & 呫 & $\stackrel{\infty}{=}$ & 0 & $\stackrel{\mathbb{N}}{\underline{N}}$ & : & 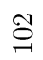 & $\vec{\bullet}$ & $p$ & $\mathbb{\infty}^{\prime \prime}$ & $\underset{\mathcal{I}}{ }$ \\
\hline 'ا & $\otimes_{\infty}$ & $\mathscr{f}$ & $\stackrel{\widehat{0}}{9}$ & 0 & $\vec{\infty}$ & î & $\exists$ & 6 & 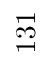 & 8 & $\stackrel{59}{N}$ & İ & $\stackrel{\infty}{\sim}$ & $\underset{I}{\mathbb{I}}$ & $\stackrel{8}{\circ}$ & $\underset{\sim}{\vec{\infty}}$ & 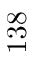 & 독 & $\stackrel{\infty}{\sim}$ \\
\hline إن & $\stackrel{\sim}{\sim}$ & 0 & 0 & $\stackrel{5}{50}$ & $\stackrel{R}{R}$ & 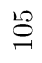 & $\stackrel{R}{R}$ & $\sigma$ & $\stackrel{\infty}{\mathcal{I}}$ & 告 & $\stackrel{\curvearrowright}{\curvearrowright}$ & $\underset{\sim}{\stackrel{8}{\sim}}$ & $\stackrel{9}{\rightarrow}$ & $\stackrel{\infty}{\sim}$ & 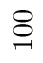 & 0 & 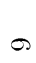 & $\Xi$ & 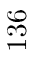 \\
\hline 'ان & 年 & 0 & 0 & $\mathscr{f}$ & $\stackrel{\text { 昜 }}{\circ}$ & 号 & ヘึ & $\stackrel{\sim}{\sigma}$ & 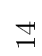 & $\stackrel{\leftrightarrow}{\stackrel{0}{\rightarrow}}$ & : & $\hat{0}$ & $\stackrel{\infty}{\sim}$ & 考 & $\stackrel{\infty}{\leftrightarrow}$ & $\exists$ & $\stackrel{\varphi}{\oplus}$ & $\stackrel{\Im}{\Im}$ & $\therefore$ \\
\hline 'إ & 0 & 年 & $\stackrel{\sim}{\sim}$ & $\varnothing$ & $i$ & $\exists$ & $\overrightarrow{\mathcal{I}}$ & $\mathbb{F}$ & $\stackrel{\infty}{\circ}$ & $\stackrel{20}{\rightarrow}$ & $\underset{\sim}{\infty}$ & $\stackrel{\vec{\infty}}{=}$ & $\stackrel{10}{\rightarrow}$ & $\underset{\exists}{\exists}$ & 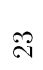 & $\neg$ & 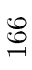 & 点 & $\widehat{\infty}$ \\
\hline $\bar{g}$ & $\rightarrow$ & $v_{1}$ & $\infty$ & $\nabla$ & ${ }_{0}$ & 0 & - & w & $\sigma$ & $\stackrel{?}{\rightarrow}$ & 1 & $\mathcal{I}$ & $\stackrel{2}{\rightarrow}$ & T & $\stackrel{19}{7}$ & in & $0 \Omega$ & $\infty$ & 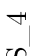 \\
\hline $\bar{\Xi}$ & 0 & $0^{\prime}$ & O & 0 & 0 & O & 0 & 0 & 0 & 0 & O & 0 & ' & 0 & 0 & Dn & S & $\frac{v}{b 2}$ & 足 \\
\hline
\end{tabular}


Instance 4_20_3_3:

Table A.20. General information of instance.

\begin{tabular}{llll}
\hline Description & Variable & Value & Unit \\
\hline No. of possible supply stations & I & 4 & {$[-]$} \\
No. of demand locations & $D$ & 20 & {$[-]$} \\
No. of vehicles & $V$ & 3 & {$[-]$} \\
No. of routes & K & 3 & {$[-]$} \\
No. of machines & $M$ & 1 & {$[-]$} \\
\hline
\end{tabular}

Table A.21. Daily demand, opening costs and raw material cost of instance.

\begin{tabular}{|c|c|c|c|c|}
\hline Location & Demand[m3/day] & $\begin{array}{l}\text { Supply } \\
\text { Station }\end{array}$ & $\begin{array}{l}\text { Opening cost } \\
{[\$ / \text { day }]}\end{array}$ & $\begin{array}{l}\text { Raw material } \\
\text { cost }[\$ / \mathrm{m} 3]\end{array}$ \\
\hline C__1 & 9,856 & $\mathrm{SS} \_1$ & 195.69 & 0.1357 \\
\hline C__2 & 11,844 & $\mathrm{SS} \_2$ & 195.69 & 0.1393 \\
\hline C_3 & 2,688 & SS_3 & 195.69 & 0.1429 \\
\hline C_4 & 3,388 & SS_4 & 195.69 & 0.1464 \\
\hline C_5 & 1,624 & & & \\
\hline C_6 6 & 7,168 & & & \\
\hline C_ 7 & 6,776 & & & \\
\hline C_8 8 & 10,332 & & & \\
\hline C_9 & 3,108 & & & \\
\hline C__10 & 13,020 & & & \\
\hline C__11 & 7,532 & & & \\
\hline C__12 & 11,480 & & & \\
\hline C__13 & 2,492 & & & \\
\hline C__14 & 6,468 & & & \\
\hline C__15 & 1,624 & & & \\
\hline C__16 & 4,424 & & & \\
\hline C__ 17 & 13,468 & & & \\
\hline C__18 & 10,024 & & & \\
\hline C__19 & 3,892 & & & \\
\hline C__20 & 6,076 & & & \\
\hline
\end{tabular}




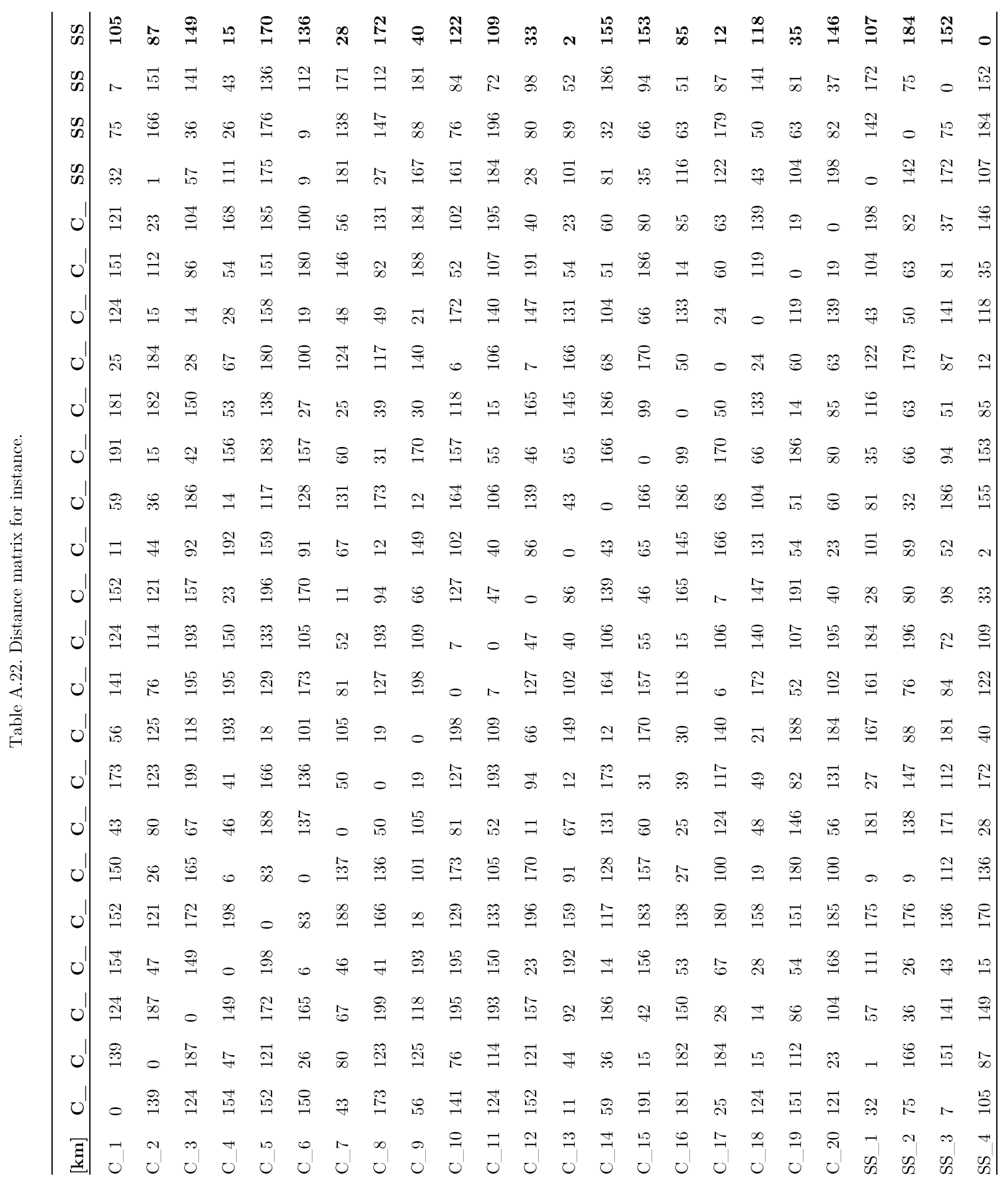


Instance 4_25_4_4:

Table A.23. General information of instance.

\begin{tabular}{llll}
\hline Description & Variable & Value & Unit \\
\hline No. of possible supply stations & I & 4 & {$[-]$} \\
No. of demand locations & $D$ & 25 & {$[-]$} \\
No. of vehicles & $V$ & 4 & {$[-]$} \\
No. of routes & $\mathrm{K}$ & 4 & {$[-]$} \\
No. of machines & $M$ & 1 & {$[-]$} \\
\hline
\end{tabular}

Table A.24. Daily demand, opening costs and raw material cost of instance.

\begin{tabular}{|c|c|c|c|c|}
\hline Location & $\begin{array}{l}\text { Demand } \\
{[\mathrm{m} 3 / \text { day }]}\end{array}$ & $\begin{array}{l}\text { Supply } \\
\text { Station }\end{array}$ & $\begin{array}{l}\text { Opening cost } \\
{[\$ / \text { day }]}\end{array}$ & $\begin{array}{l}\text { Raw material } \\
\text { cost }[\$ / \mathrm{m} 3]\end{array}$ \\
\hline C__1 & 2,352 & SS_1 & 195.69 & 0.1357 \\
\hline C_2 & 5,880 & SS $\_2$ & 195.69 & 0.1393 \\
\hline C_3 & 1,484 & SS $\_3$ & 195.69 & 0.1429 \\
\hline C_4 & 4,424 & SS_4 & 195.69 & 0.1464 \\
\hline C_5 & 10,220 & & & \\
\hline C_6 & 3,500 & & & \\
\hline C_7 & 1,876 & & & \\
\hline C__ 8 & 6,244 & & & \\
\hline C_ 9 & 1,624 & & & \\
\hline C_10 & 7,448 & & & \\
\hline C_11 & 4,424 & & & \\
\hline C_12 & 9,492 & & & \\
\hline C_13 & 1,624 & & & \\
\hline C_14 & 7,448 & & & \\
\hline C_15 & 5,264 & & & \\
\hline C_16 & 952 & & & \\
\hline C_17 & 7,588 & & & \\
\hline C_18 & 3,948 & & & \\
\hline C_19 & 6,748 & & & \\
\hline C_20 & 9,604 & & & \\
\hline C_21 & 2,940 & & & \\
\hline C_22 & 8,540 & & & \\
\hline C_23 & 4,592 & & & \\
\hline C_24 & 7,168 & & & \\
\hline C__25 & 1,876 & & & \\
\hline
\end{tabular}




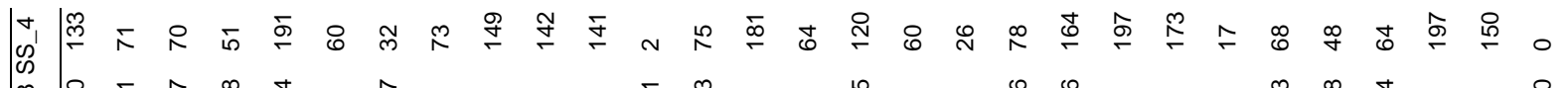

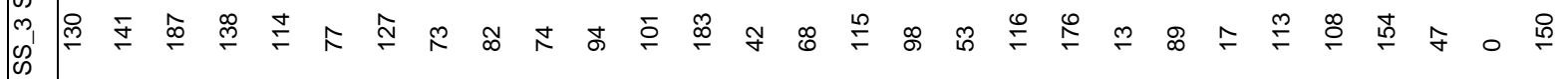

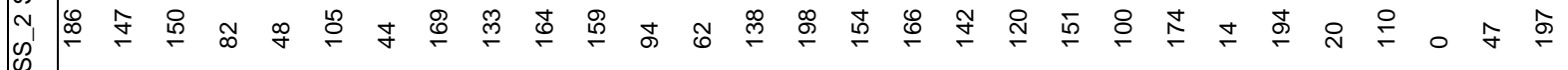
卢 $\mathscr{N}_{1}$ న

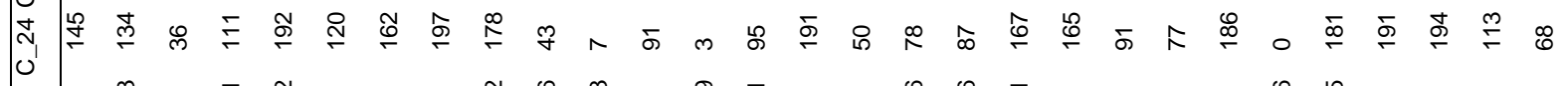
霍 等 $\bar{N}_{1}$ 人 更 更 唄

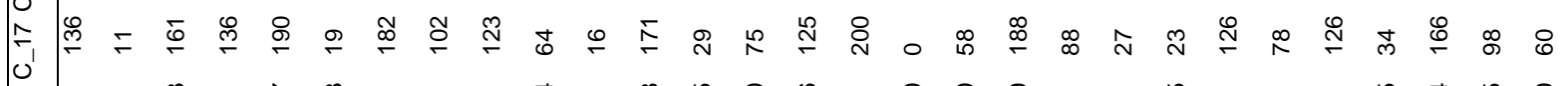
萑 峁 苟 倠 닌 更 ర)

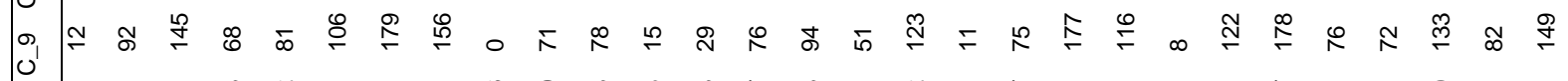

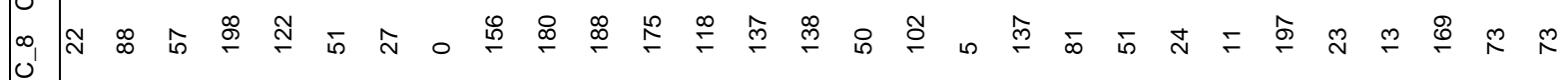
仙

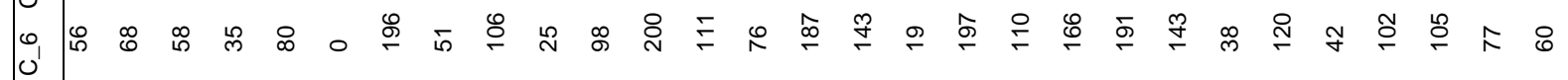
ద

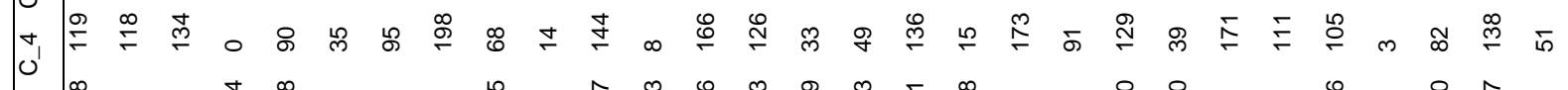

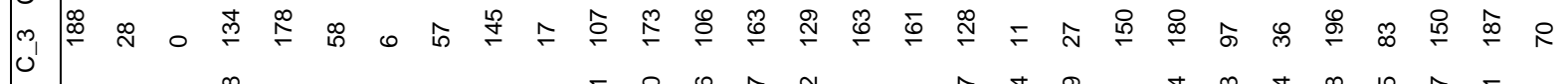
N J

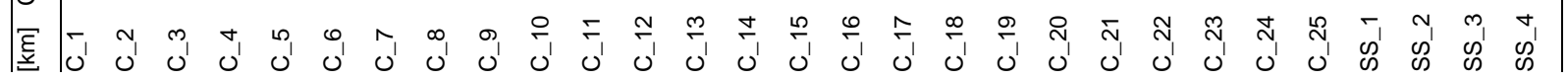


Instance $5 \_10 \_2 \_3$ :

Table. General information of instance A.26.

\begin{tabular}{llll}
\hline Description & Variable & Value & Unit \\
\hline No. of possible supply stations & $\mathrm{I}$ & 5 & {$[-]$} \\
No. of demand locations & $D$ & 10 & {$[-]$} \\
No. of vehicles & $V$ & 2 & {$[-]$} \\
No. of routes & $\mathrm{K}$ & 3 & {$[-]$} \\
No. of machines & & & {$[-]$} \\
\end{tabular}

Table A.27. Daily demand, opening costs and raw material cost of instance.

\begin{tabular}{|c|c|c|c|c|}
\hline Location & $\begin{array}{l}\text { Demand } \\
{[\mathrm{m} 3 / \text { day }]}\end{array}$ & $\begin{array}{l}\text { Supply } \\
\text { Station }\end{array}$ & $\begin{array}{l}\text { Opening cost } \\
{[\$ / \text { day }]}\end{array}$ & $\begin{array}{l}\text { Raw material } \\
\text { cost }[\$ / \mathrm{m} 3]\end{array}$ \\
\hline C__1 & 700 & SS_1 & 195.69 & 0.1500 \\
\hline C__2 & 1,288 & $\mathrm{SS} \_2$ & 195.69 & 0.1464 \\
\hline C_ 3 & 8,344 & $\mathrm{SS} \_3$ & 195.69 & 0.1429 \\
\hline C_ 4 & 3,388 & SS_ 4 & 195.69 & 0.1393 \\
\hline C_ 5 & 11,788 & SS_5 & 195.69 & 0.1357 \\
\hline C_ 6 & 12,012 & & & \\
\hline C_ 7 & 13,496 & & & \\
\hline C_ 8 & 6,860 & & & \\
\hline C_ 9 & 3,108 & & & \\
\hline C__10 & 3,192 & & & \\
\hline
\end{tabular}


242

S. López-Ruíz, R. B. Carmona-Benítez / Journal of Applied Research and Technology 17 (2019) 213-249

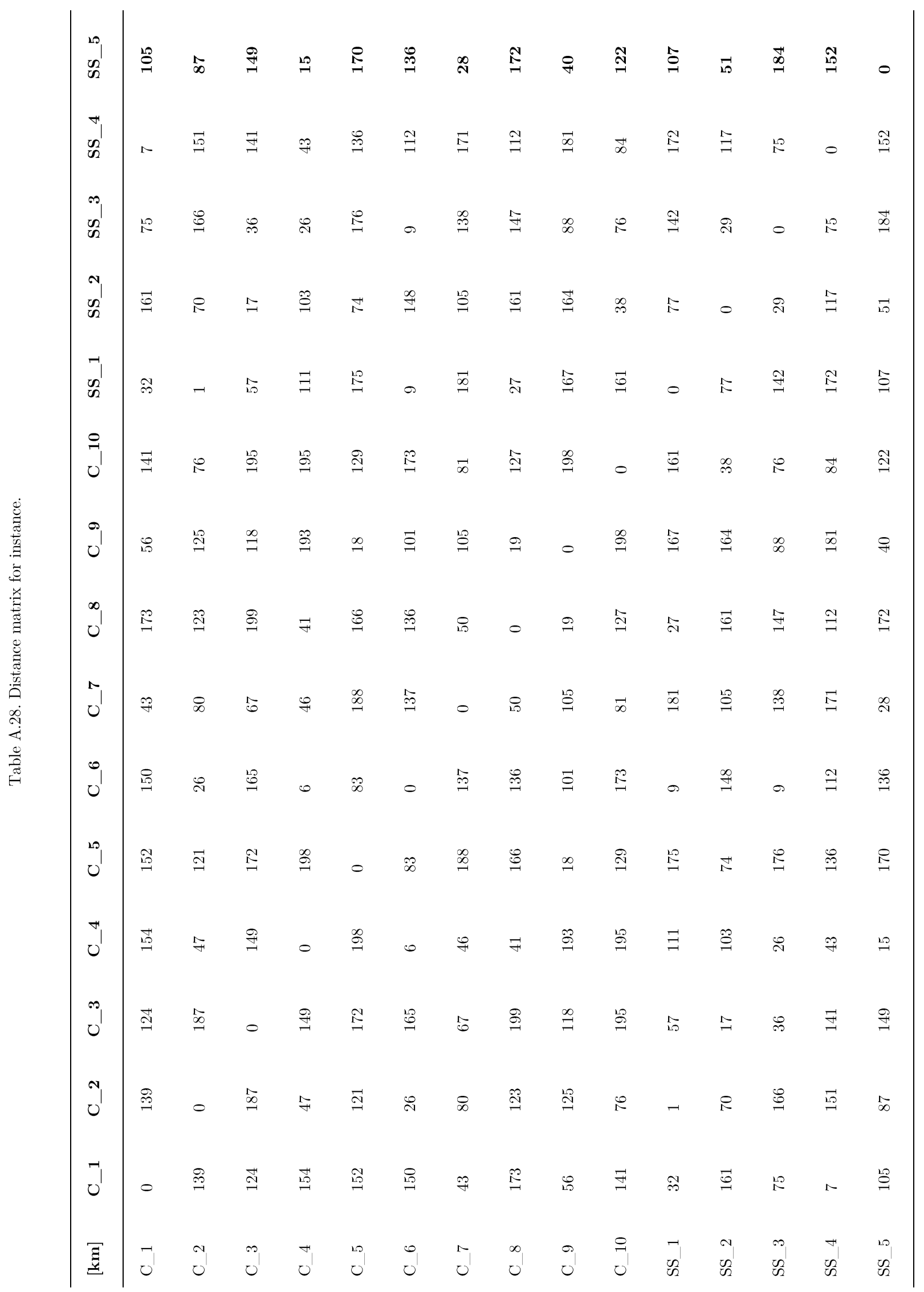


Instance $\begin{array}{llll}5 & 15 & 2 & 3 \text { : }\end{array}$

Table A.29. General information of instance.

\begin{tabular}{llll}
\hline Description & Variable & Value & Unit \\
\hline No. of possible supply stations & $\mathrm{I}$ & 5 & {$[-]$} \\
No. of demand locations & $D$ & 15 & {$[-]$} \\
No. of vehicles & $V$ & 2 & {$[-]$} \\
No. of routes & $\mathrm{K}$ & 3 & {$[-]$} \\
No. of machines & $M$ & 1 & {$[-]$} \\
\hline
\end{tabular}

Table A.30. Daily demand, opening costs and raw material cost of instance.

\begin{tabular}{lllll}
\hline Location & $\begin{array}{l}\text { Demand } \\
{[\mathbf{m 3} / \text { day }]}\end{array}$ & $\begin{array}{l}\text { Supply } \\
\text { Station }\end{array}$ & $\begin{array}{l}\text { Opening } \\
{[\$ / \text { day }]}\end{array}$ & $\begin{array}{l}\text { Raw } \\
\text { cost }[\$ \mathbf{m 3}]\end{array}$ \\
\hline C_1 & 700 & SS_1 & 195.69 & 0.1500 \\
C_2 & 1,288 & SS_2 & 195.69 & 0.1464 \\
C_3 & 8,344 & SS_3 & 195.69 & 0.1429 \\
C_4 & 3,388 & SS_4 & 195.69 & 0.1393 \\
C_5 & 11,788 & SS_5 & 195.69 & 0.1357 \\
C_6 & 12,012 & & & \\
C_7 & 13,496 & & & \\
C_8 & 6,860 & & & \\
C_9 & 3,108 & & & \\
C_10 & 3,192 & & \\
C_11 & 7,532 & & \\
C_12 & 10,696 & & & \\
C_13 & 4,872 & & & \\
C_14 & 6,468 & & & \\
C_15 & 8,960 & & & \\
\hline
\end{tabular}




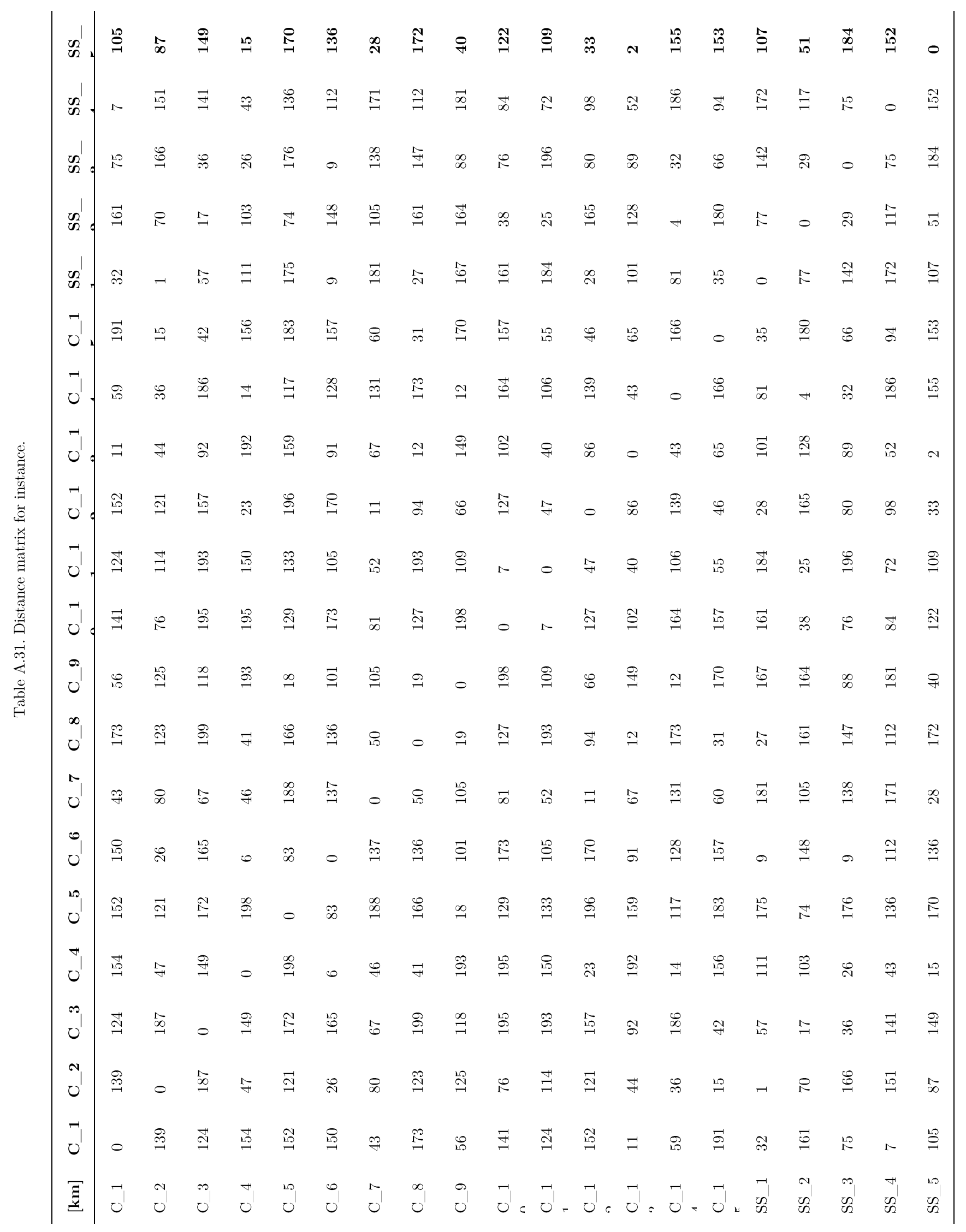


Instance $5 \_20 \_3 \_3$ :

Table A.32. General information of instance.

\begin{tabular}{llll}
\hline Description & Variable & Value & Unit \\
\hline No. of possible supply stations & $\mathrm{I}$ & 5 & {$[-]$} \\
No. of demand locations & $D$ & 20 & {$[-]$} \\
No. of vehicles & $V$ & 3 & {$[-]$} \\
No. of routes & $\mathrm{K}$ & 3 & {$[-]$} \\
No. of machines & $M$ & 1 & {$[-]$} \\
\hline
\end{tabular}

Table A.33. Daily demand, opening costs and raw material cost of instance.

\begin{tabular}{lllll}
\hline Location & $\begin{array}{l}\text { Demand } \\
{[\mathrm{m3} / \text { day }]}\end{array}$ & $\begin{array}{l}\text { Supply } \\
\text { Station }\end{array}$ & $\begin{array}{l}\text { Opening } \\
\mathbf{t}[\mathbf{\$} / \text { day }]\end{array}$ & $\begin{array}{c}\text { cos } \\
\text { Raw } \\
\text { material cost } \\
{[\$ / \mathrm{m} 3]}\end{array}$ \\
\hline C_1 & 700 & SS_1 & 195.69 & 0.1500 \\
C_2 & 1,288 & SS_2 & 195.69 & 0.1464 \\
C_3 & 8,344 & SS_3 & 195.69 & 0.1429 \\
C_4 & 3,388 & SS_4 & 195.69 & 0.1393 \\
C_5 & 11,788 & SS_5 & 195.69 & 0.1357 \\
C_6 & 12,012 & & & \\
C_7 & 13,496 & & & \\
C_8 & 6,860 & & & \\
C_9 & 3,108 & & & \\
C_10 & 3,192 & & & \\
C_11 & 7,532 & & & \\
C_12 & 10,696 & & & \\
C_13 & 4,872 & & & \\
C_14 & 6,468 & & & \\
C_15 & 8,960 & & & \\
C_16 & 12,852 & & \\
C_17 & 2,268 & & & \\
C_18 & 10,024 & & & \\
C_19 & 8,092 & & & \\
C_20 & 6,076 & & & \\
\hline
\end{tabular}




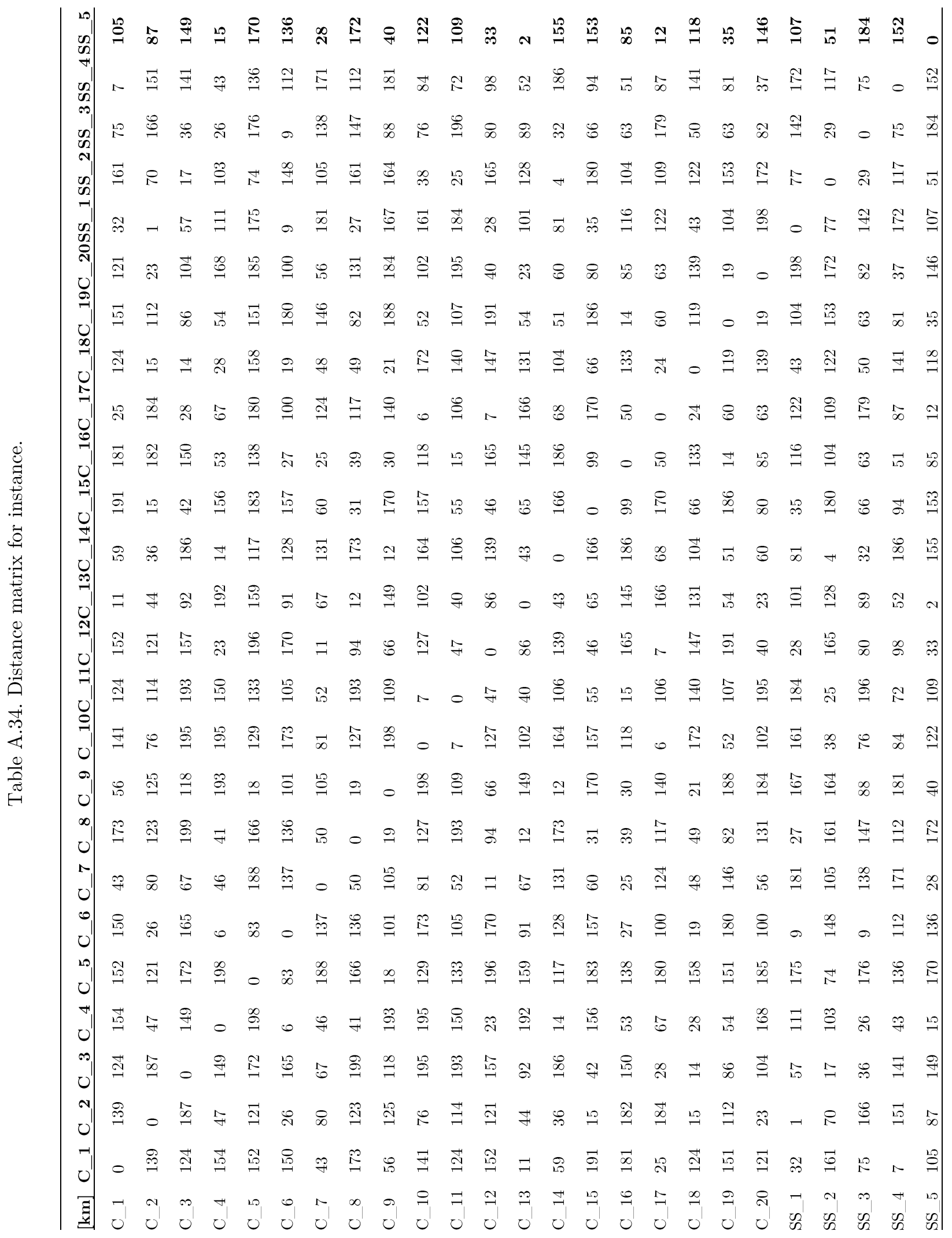


Instance $5 \_25 \_4 \quad 4$ :

Table A.35. General information of instance.

\begin{tabular}{llll}
\hline Description & Variable & Value & Unit \\
\hline No. of possible supply stations & $\mathrm{I}$ & 5 & {$[-]$} \\
No. of demand locations & $D$ & 25 & {$[-]$} \\
No. of vehicles & $V$ & 4 & {$[-]$} \\
No. of routes & $\mathrm{K}$ & 4 & {$[-]$} \\
No. of machines & $M$ & 1 & {$[-]$} \\
\hline
\end{tabular}

Table A.36. Daily demand, opening costs and raw material cost of instance.

\begin{tabular}{|c|c|c|c|c|}
\hline Location & $\begin{array}{l}\text { Demand } \\
{[\mathrm{m} 3 / \text { day }]}\end{array}$ & $\begin{array}{l}\text { Supply } \\
\text { Station }\end{array}$ & $\begin{array}{l}\text { Opening cost } \\
{[\$ / \text { day }]}\end{array}$ & $\begin{array}{l}\text { Raw } \\
\text { material cost } \\
{[\$ / \mathrm{m} 3]}\end{array}$ \\
\hline C__1 & 2,352 & SS_1 & 195.69 & 0.1500 \\
\hline C__ 2 & 5,880 & $\mathrm{SS} \_2$ & 195.69 & 0.1464 \\
\hline C_3 & 1,484 & SS_3 & 195.69 & 0.1429 \\
\hline C_ 4 & 4,424 & $\mathrm{SS} \_4$ & 195.69 & 0.1393 \\
\hline C_5 & 10,220 & $\mathrm{SS} \_5$ & 195.69 & 0.1357 \\
\hline C_6 & 3,500 & & & \\
\hline C_ 7 & 1,876 & & & \\
\hline C_ 88 & 6,244 & & & \\
\hline C__9 & 1,624 & & & \\
\hline C__10 & 7,448 & & & \\
\hline C_11 & 4,424 & & & \\
\hline C_1 12 & 9,492 & & & \\
\hline C_13 & 1,624 & & & \\
\hline C__14 & 7,448 & & & \\
\hline C__15 & 5,264 & & & \\
\hline$C_{-} 16$ & 952 & & & \\
\hline C__17 & 7,588 & & & \\
\hline C_18 & 3,948 & & & \\
\hline C__19 & 6,748 & & & \\
\hline C__20 & 9,604 & & & \\
\hline C__21 & 2,940 & & & \\
\hline C__22 & 8,540 & & & \\
\hline C__23 & 4,592 & & & \\
\hline C__24 & 7,168 & & & \\
\hline C__25 & 1,876 & & & \\
\hline
\end{tabular}




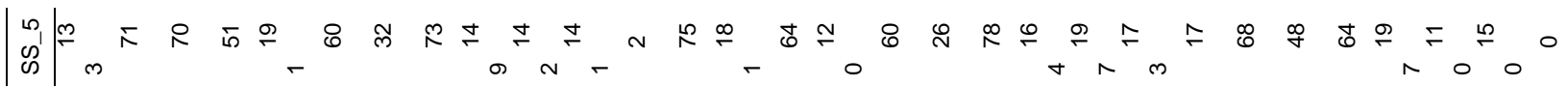
穴

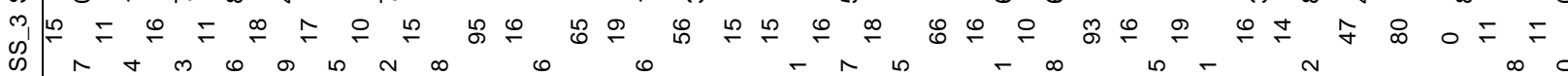

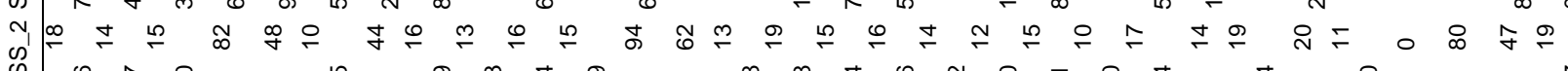
尚

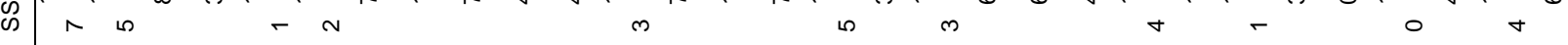
悢 嵌

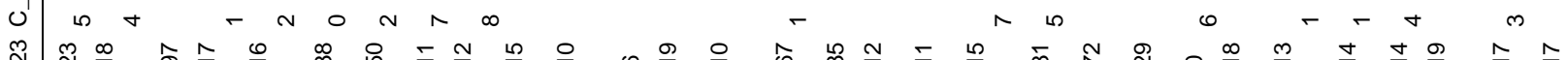

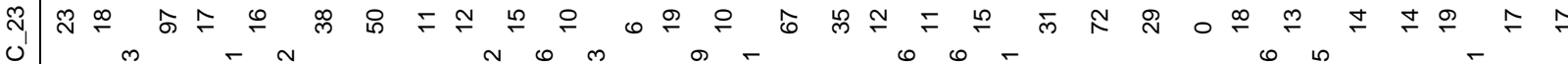

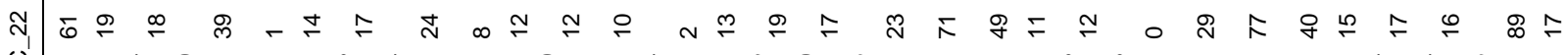
人 న

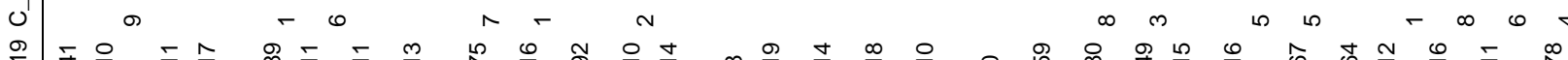

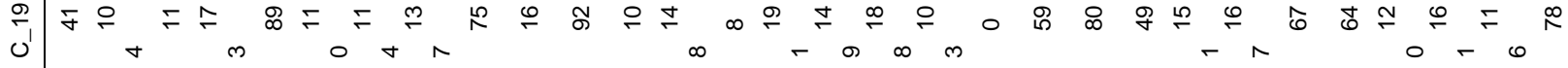
舟

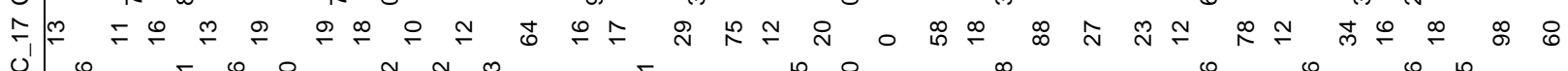
西

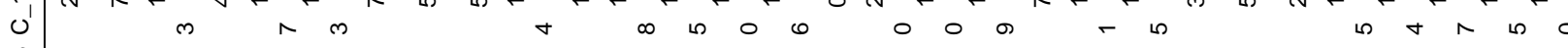

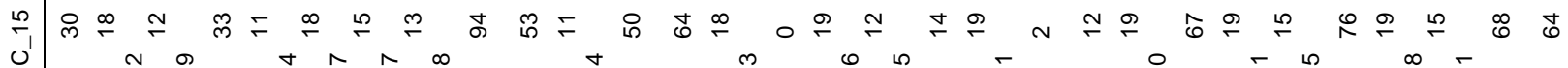
苟 药

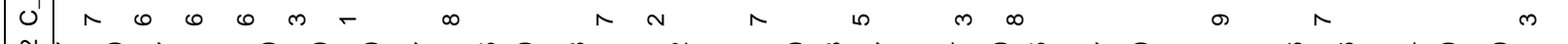
U. 更 ర)

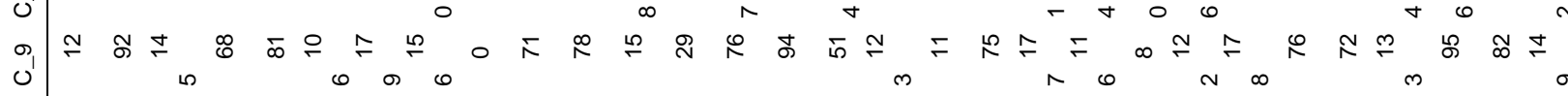

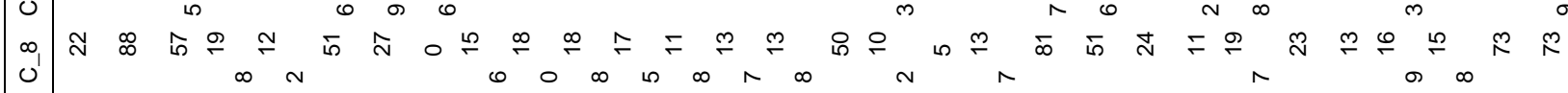
U. ○ م

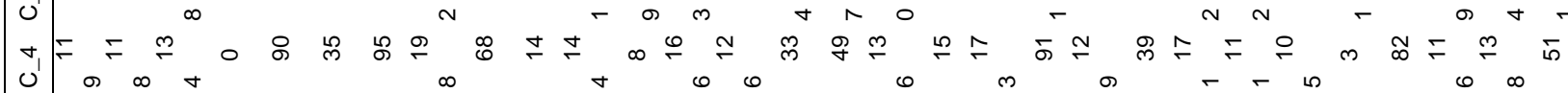

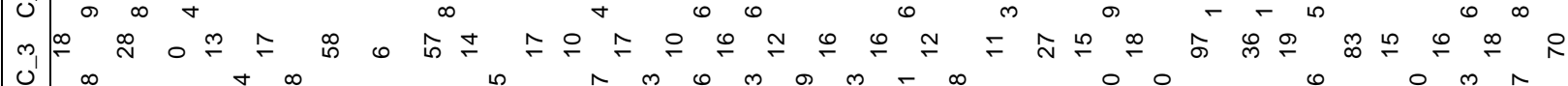

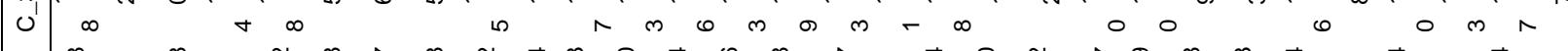

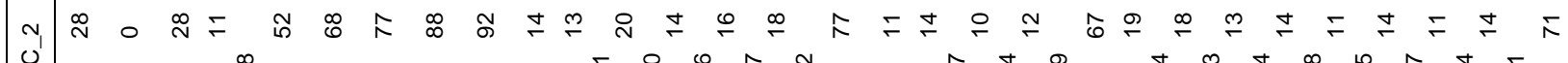
ᄀ

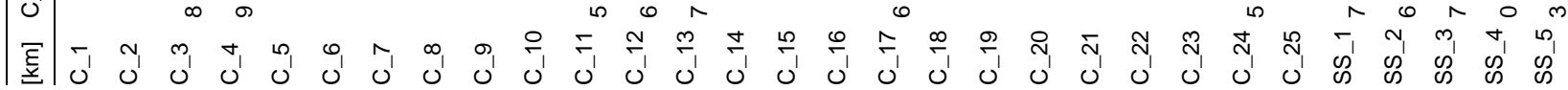




\section{REFERENCES}

Archetti, C., \& Speranza, M. G. (2008). The Split Delivery Vehicle Routing Problem: A Survey. Operations Research / Computer Science Interfaces, 43, 103-122.

Baldacci, R., Battarra, M., \& Vigo, D. (2008). Routing a Heterogeneous Fleet of Vehicles. Latest Advances and New Challenges. Operations Research/Computer Science Interfaces, 43, 3-27.

Braysy, O., \& Gendreau, M. (2005). Vehicle Routing Problem with Time Windows, Part I: Route Construction and Local Search Algorithms. Transportation Science, 39(1), 104-118.

Coelho, L. C., \& Laporte, G. (2013). The exact solution of several classes of inventory-routing problems. Computers 83 Operations Research, 40(2), 558-565.

Current, J., Ratick, S., \& Revelle, C. (1997). Dynamic facility location when the total number of facilities is uncertain: A decision analysis approach. European Journal of Operational Research, 110(3), 597-609.

Dantzig, G., \& Ramser, J. (1959). The truck dispatching problem. Management Science, 6(1), 80-91.

Flood, M. (1956). The traveling-salesman problem. Operations Research, 4(1), 61-75.
Goel, A., \& Gruhn, V. (2008). A General Vehicle Routing Problem. European Journal of Operational Research, 191(3), 650-660.

Mancini, S. (2016). A real-life Multi Depot Multi Period Vehicle Routing Problem with a Heterogeneous Fleet: Formulation and Adaptive Large Neighborhood Search based Metaheuristics. Transport Research Part C: Emerging Technologies, 70, 100-112.

Miranda P. A., \& Garrido, R. A. (2004). Incorporating inventory control decisions into a strategic distribution network design model with stochastic demand. Transportation Research Part E: Logistics and Transportation Review, 40(3), 183-207.

Owen, S. H., \& Daskin, M. S. (1998). Strategic facility location: A review. European Journal of Operational Research, 111, 423-447.

Pillac, V., Gendreau, M., Guéret, C., \& Medaglia, A. L. (2013). A review of dynamic vehicle routing problems. European Journal of Operational Research, 225(1), 1-11.

Vidal, C. J., \& Goetschalckx, M. (1997). Strategic productiondistribution models: A critical review with emphasis on global supply chain models. European Journal of Operational Research, 98(1), 1-18. 